AperTO - Archivio Istituzionale Open Access dell'Università di Torino

\title{
CHAPTER 4. Raman, IR and INS Characterization of Functionalized Carbon Materials
}

\section{This is the author's manuscript}

Original Citation:

\section{Availability:}

This version is available http://hdl.handle.net/2318/1686864

since 2019-01-15T17:57:02Z

Publisher:

ROYAL SOCIETY OF CHEMISTRY

Published version:

DOI:10.1039/9781788013116-00103

Terms of use:

Open Access

Anyone can freely access the full text of works made available as "Open Access". Works made available under a Creative Commons license can be used according to the terms and conditions of said license. Use of all other works requires consent of the right holder (author or publisher) if not exempted from copyright protection by the applicable law. 


\section{CHAPTER 4}

\section{Raman, IR and INS characterization of functionalized carbon materials}

E. Groppo, ${ }^{a}$ F. Bonino ${ }^{a}$, F. Cesano ${ }^{a}$, A. Damin ${ }^{a}$ and M. Manzoli ${ }^{b^{*}}$

${ }^{a}$ Università degli Studi di Torino, Department of Chemistry, NIS and INSTM Reference Centre, Via G.

Quarello 15, I-10135 and Via P. Giuria 7, I-10125, Torino, Italy.

${ }^{\mathrm{b}}$ Università degli Studi di Torino, Department of Drug Science and Technology, NIS and INSTM Reference Centre, Via P. Giuria 9, 10125 Torino, Italy.

*Corresponding contributor. E-mail: maela.manzoli@unito.it 


\begin{abstract}
Vibrational spectroscopies represent a powerful tool to investigate the structural properties at an atomic level. In particular, the analysis of the spectra allows to have detailed information on both structure and chemical environment of different sites. Therefore, the spectroscopic characterization can usefully assist in the comprehension of the parameters ruling the unique catalytic properties of metal-free carbon materials, as well as to implement the knowledge in the design of new C-containing systems. Keeping in mind these purposes, the present Chapter tries to provide some insights on the information obtained by using vibrational spectroscopies to characterize carbonaceous materials. Intriguing and quite recently investigated systems will be illustrated as "case histories" to show what can be learned from the analysis of the spectra collected in different experimental conditions.

The results concerning activated carbons, carbon nanotubes, graphene oxide as well as carbon nitrides or fullerenes will be discussed in order to investigate the effect of the pretreatment and of the functionalization/doping on the catalytic activity in different applications.
\end{abstract}




\subsection{Raman spectroscopy applied to carbons}

Raman spectroscopy is based on the inelastic light scattering of a laser source in the near IR - UV range. Backscattered photons come out with a lower $\left(v_{0}-v_{\text {vibr }}\right)$ or higher $\left(v_{0}+v v i b r\right)$ energy with respect to the incoming laser photons $\left(v_{0}\right)$. The energy difference $\left(v_{\text {vibr }}\right)$ corresponds to the vibrational mode. A Raman active vibrational mode should involve a change in the electric polarizability. This powerful technique is widely adopted in the characterization of carbon derived materials, both crystalline [e.g. HOPG (highly oriented pyrolytic graphite), nano-graphite] or amorphous (e.g. turbostratic carbon, carbon fibers etc.).

\subsubsection{Raman spectroscopy of perfect and defective graphite}

The Raman spectrum of perfect graphite (e.g. HOPG) with large crystalline domains is dominated by a sharp peak centred at $1580 \mathrm{~cm}^{-1}$ (historically indicated as $\mathrm{G}$ peak, first order, see Figure 1a, top), which is attributed to a $E_{2 g}$ mode (Figure 1c, part A). In addition, a complex envelope of bands appears in the 2800$2600 \mathrm{~cm}^{-1}$ region (second order), mostly due to combination modes. In particular, two main peaks are observed in the spectrum of perfect graphite, originally indicated as $\mathrm{G}_{2}^{\prime}$ (high frequency side, sharp) and $\mathrm{G}_{1}^{\prime}$ (low frequency side, broad). ${ }^{1-3}$
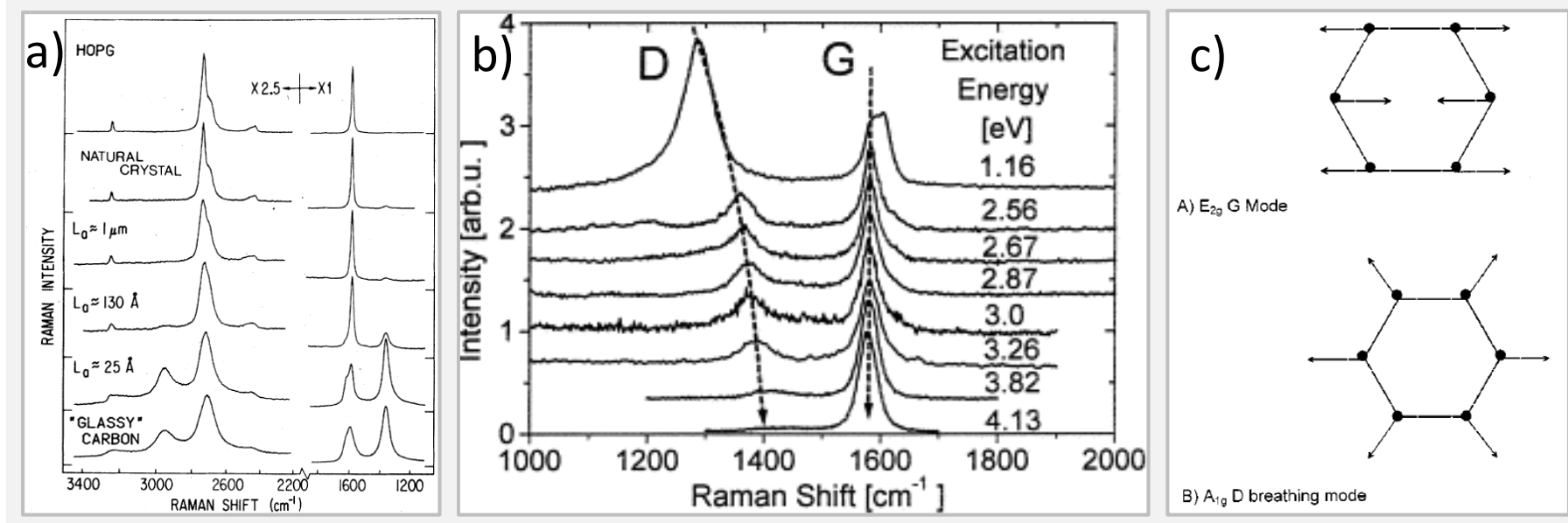

Figure 1. Part a) First- (right side) and second-order (left side) Raman spectra of different forms of graphite, from perfect (top) to very defective up to glassy carbon (bottom). Reprinted (figure 8) with permission from R. J. Nemanich, S. A. Solin, Phys. Rev. B, 20, 392, 1979. Copyright (1979) by the American Physical Society. Part b) Raman spectra of graphite excited by different laser lines. Reprinted from J. Non. Cryst. Solids, 227-230, I. Pócsik, M. Hundhausen, M. Koós, L. Ley, Origin of the D peak in the Raman spectrum of microcrystalline graphite, 1083-1086, Copyright (1998) with permission from Elsevier. Part c) Pictorial representation of the $\mathrm{G}$ and $\mathrm{D}$ vibrational modes. Reprinted (figure 4) with permission from A. C. Ferrari, J. Robertson, Phys. Rev. B, 61, 14095, 2000. Copyright (2000) by the American Physical Society. 
Moving to less perfect systems (Figure 1a, from top to bottom), a new peak (historically indicated as D peak, $A_{l g}$ symmetry) located around $1350 \mathrm{~cm}^{-1}$ starts to appear. This band is usually assigned to a lattice breathing mode that is forbidden in graphite, but becomes active in the presence of structural disorder (Figure 1c, part B). Since long time, the intensity ratio between the $D$ and $G$ bands $\left(I_{D} / I_{G}\right)$ has been inversely correlated with carbon cluster dimension according to the Tuinstra-Koenig correlation (TK) and considered as an indicator of the size of the graphitic domains in $\mathrm{sp}^{2}$ carbonaceous materials (see Figure $2 \mathrm{~b}$, right part). Therefore the $\mathrm{I}_{\mathrm{D}} / \mathrm{I}_{\mathrm{G}}$ ratio can be usefully employed to classify the carbon materials in terms of crystallinity and/or domains dimension. Due to the fact that $\mathrm{G}_{2}^{\prime}$ and $\mathrm{G}_{1}{ }_{1}$ falls quite near to overtone region of the $\mathrm{D}$ peak, they are now re-classified as second order D peak and typically indicated as $2 \mathrm{D}$, instead of the original nomenclature. Another interesting aspect characterizing the D peak is the strong dependence of its position (and of its intensity too) with respect to the exciting laser line adopted to collect the Raman spectrum. ${ }^{4}$ Such effect is clearly shown in Figure 1b, that reports the Raman spectra of a defective graphite collected by adopting different exciting laser lines falling in the 1.16-4.13 eV (1069-300 $\mathrm{nm})$. This behaviour suggests a strong coupling between the phonon dispersion and the electronic structure of carbon derived materials.

\subsubsection{Raman spectroscopy of activated carbons}

Raman spectroscopy is among the most powerful technique to study the structure of activated carbons. These materials are entirely composed by aromatic C-C bonds without any dipole moment, but with a good polarizability. Typically the laser lines at $514 \mathrm{~nm}$ and $244 \mathrm{~nm}$ are adopted as exciting sources. The former gives information mainly on the $\mathrm{sp}^{2}$ domains, while the latter conveys information on both $\mathrm{sp}^{2}$ and $\mathrm{sp}^{3}$ carbon species. However, the $\lambda=514 \mathrm{~nm}$ laser line is the most adopted in this type of study as it is the most available in Raman laboratories.

Figure 2a displays a typical Raman spectrum of an activated carbon. It is dominated by two intense bands, attributed to the vibrational modes involving $\mathrm{sp}^{2}$ carbon species belonging to disordered microcrystalline domains. ${ }^{5}$ The signal around $1600 \mathrm{~cm}^{-1}$ is the $\mathrm{G}$ band: the $+20 \mathrm{~cm}^{-1}$ shift respect to the $\mathrm{G}$ band of graphite is typical of disordered graphitic systems and due the overlap of a second band (D2, around $1620 \mathrm{~cm}^{-1}$ ), which involves surface "graphene-like" layers or $\mathrm{sp}^{2}$ nanostructures with a strained geometry. Furthermore, the position of the $\mathrm{G}$ band indicates that the graphene stacking order is very low in activated carbons and that graphite-like platelets are also partially defective. The second dominant feature around $1350 \mathrm{~cm}^{-1}$ is the D band. Recently, it has been proposed that the TK correlation is applicable only to graphitic domains having a lateral dimension larger than about $2 \mathrm{~nm}$ (Figure $2 \mathrm{~b}$, right side). ${ }^{5}$ In contrast, for $\mathrm{sp}^{2}$ platelets having dimensions below $2 \mathrm{~nm}$ the development of a D band in the Raman spectrum indicates ordering (Figure 2b, left side). 

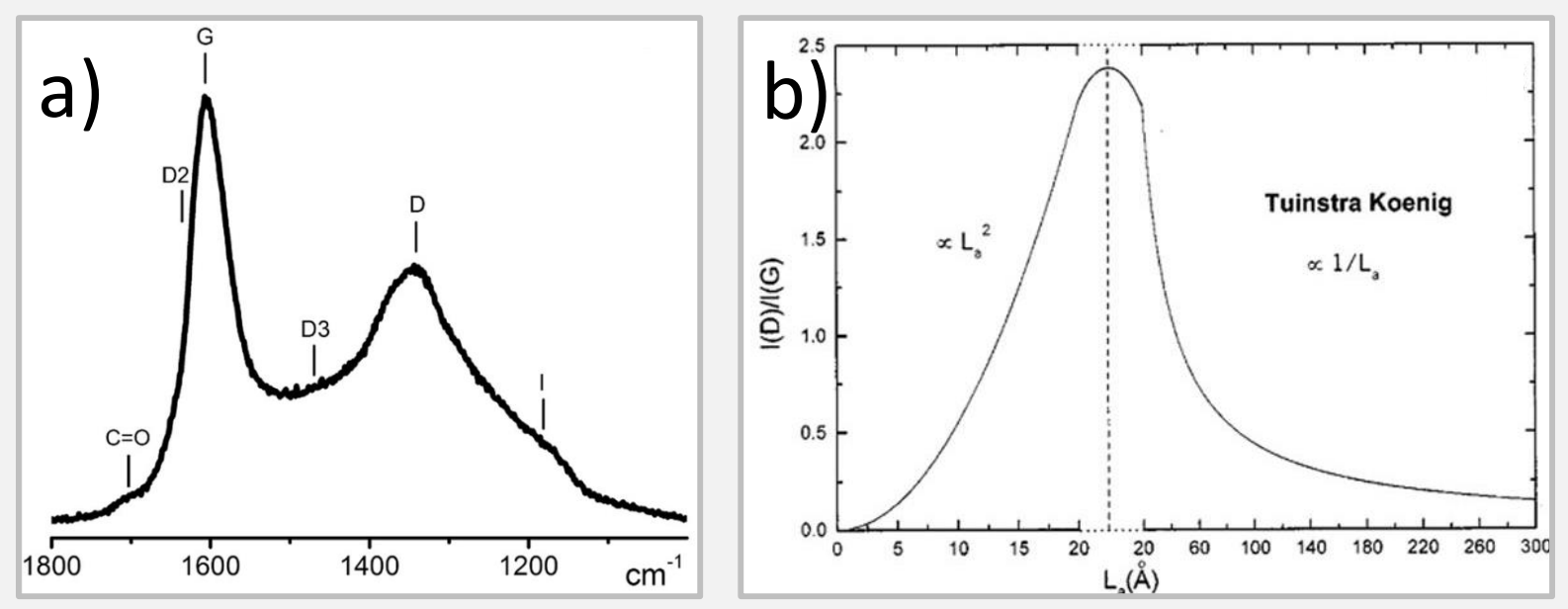

Figure 2. Part a) Typical Raman spectrum (collected with an excitation $\lambda=514 \mathrm{~nm}$ ) of a chemically activated carbon and assignment of the main absorption bands. Rend. Lincei, Activated carbons for applications in catalysis: the point of view of a physical-chemist, 28, 2017, 29, A. Lazzarini, (Copyright Accademia Nazionale dei Linceioriginal 2017). With permission of Springer. Part b) Dependence of the $\mathrm{I}(\mathrm{D}) / \mathrm{I}(\mathrm{G})$ ratio as a function of the lateral size $\left(\mathrm{L}_{\mathrm{a}}\right)$ of the $\mathrm{sp}^{2}$ domains. Reprinted (figure 5) with permission from A. C. Ferrari, J. Robertson, Phys. Rev. B, 61, 14095, 2000. Copyright (2000) by the American Physical Society.

Two additional bands are observed in the Raman spectrum shown in Figure 2a: 1) the D3 band, observed between the $\mathrm{G}$ and the $\mathrm{D}$ bands around $1450 \mathrm{~cm}^{-1}$ and ascribed to randomly distributed amorphous carbon on the interstitial position of the graphitic islands; and 2) the I band around $1150 \mathrm{~cm}^{-1}$, originated from the coexistence of $\mathrm{sp}^{3}$ phase and conjugated non-aromatic polyenes, present as pending groups of graphitic platelets. Besides, the very weak feature present around $1700 \mathrm{~cm}^{-1}$ is due to the $v(\mathrm{C}=\mathrm{O})$ vibrations of oxygenated groups at the activated carbon surface. As expected, its intensity is very weak as it is due to slightly active Raman vibrational mode and to surface species, hardly detectable by means of this spectroscopy, which is essentially devoted to bulk investigation.

\subsubsection{Raman spectroscopy of graphene, graphene oxide and reduced graphene oxide}

Raman spectroscopy is largely employed to characterize graphene in terms of number of layers, defect density, edge chirality, strain, thermal properties, and amount of doping. ${ }^{6-8}$ Indeed, the $\mathrm{G}$ band at around $1580 \mathrm{~cm}^{-1}$ is doubly-degenerate: the degeneration is lost when graphene is rolled to give a carbon nanotube. The second order 2D or $\mathrm{G}^{\prime}$ band at around $2700 \mathrm{~cm}^{-1}$ (assigned to the in-plane breathing-like mode of the carbon rings) is double resonant, and splits in four peaks in bilayer graphene. If defects are present in 
graphene, several additional symmetry-breaking features are found. In these cases, the band with the highest intensity is usually the D one. Also the $\mathrm{D}^{\prime}$ band is influenced by symmetry-breaking. Symmetry breaking is commonly due to the presence of vacancies, interstitial and substitutional atoms or to the introduction of interfaces at the borders of crystalline areas.

Concerning graphene oxide (GO, Figure $3 a)^{9}$ a typical Raman spectrum is shown in Figure $3 b$, compared to that of reduced GO (RGO) and graphene. With respect to graphene, the spectrum of GO shows both the D and $\mathrm{G}$ peaks (much broader) and a very broad 2D peak. It is well known in the literature ${ }^{10,11}$ that RGO has a Raman spectrum very similar to that of GO. Only a small increase of the $\mathrm{I}_{\mathrm{D}} / \mathrm{I}_{\mathrm{G}}$ ratio is observed. ${ }^{12,13}$ Finally, the Raman spectra of G1 (1-layer graphene) with a degree of functionalization of about 4 and $50 \%$, respectively display no significant differences (data not shown), indicating that Raman spectroscopy is scarcely sensitive to the surface functionalization. ${ }^{11}$

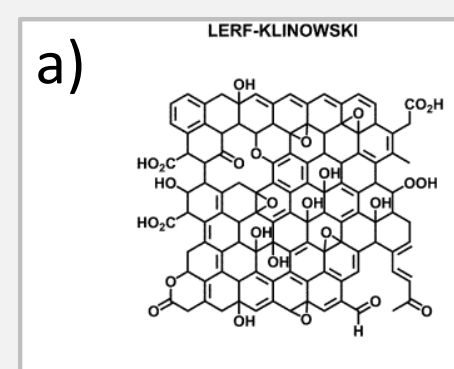

NAKAJIMA-MATSUO

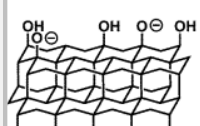
ОН $\mathrm{O}_{\mathrm{O}} \odot \mathrm{OH}$
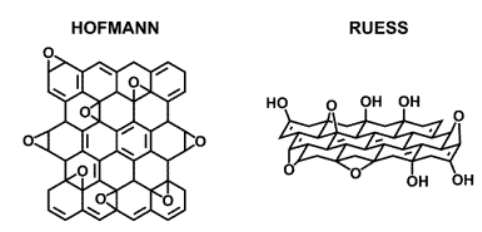

DÉKÁNY
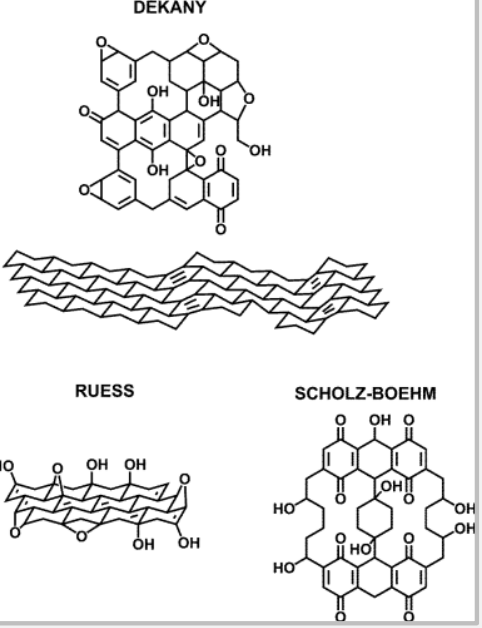

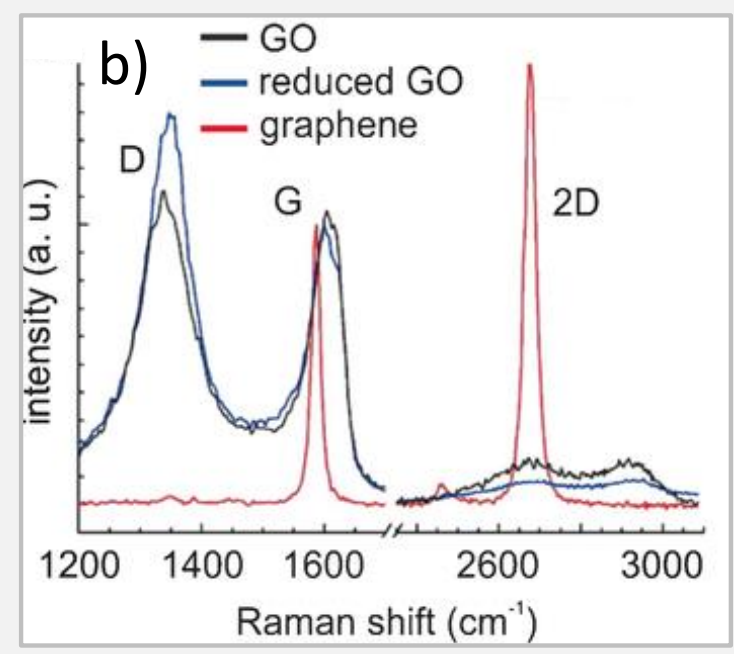

Figure 3. Part a) Structural models of GO. Reproduced from Ref. ${ }^{9}$ with permission from The Royal Society of Chemistry. Part b) Raman spectra collected from: single sheet of graphene oxide deposited from water solution (GO), thermally reduced single sheet of graphene oxide (R-GO), and single sheet of pristine graphene. Reprinted (adapted) with permission from (I. Jung, D. A. Dikin, R. D. Piner and R. S. Ruoff, Nano Lett., 2008, 8, 4283-4287). Copyright (2008) American Chemical Society.

Graphene oxide can also be intentionally doped by means of several methods (e.g. electrostatic, contact doping, chemical, substitution - mainly nitrogen or boron - and optical doping). Nitrogen-doped graphene shows better catalytic properties than the intrinsic graphene, which can be exploited in nano-devices and fuel cells. Since also amino-functionalized carbon materials display good catalytic activity, it becomes interesting to combine the amino-modification and $\mathrm{N}$-doping in graphene. In this frame, Zhang et al. ${ }^{8}$ proposed a simple and effective solvo-thermal method to synthesize amino-functionalized graphene, as 
schematically shown in Figure 4a, from graphite oxide only in the presence of ammonia solution. The resultant material is an efficient metal-free catalyst, exhibiting enhanced electro-catalytic properties for Oxygen Reduction Reactions.
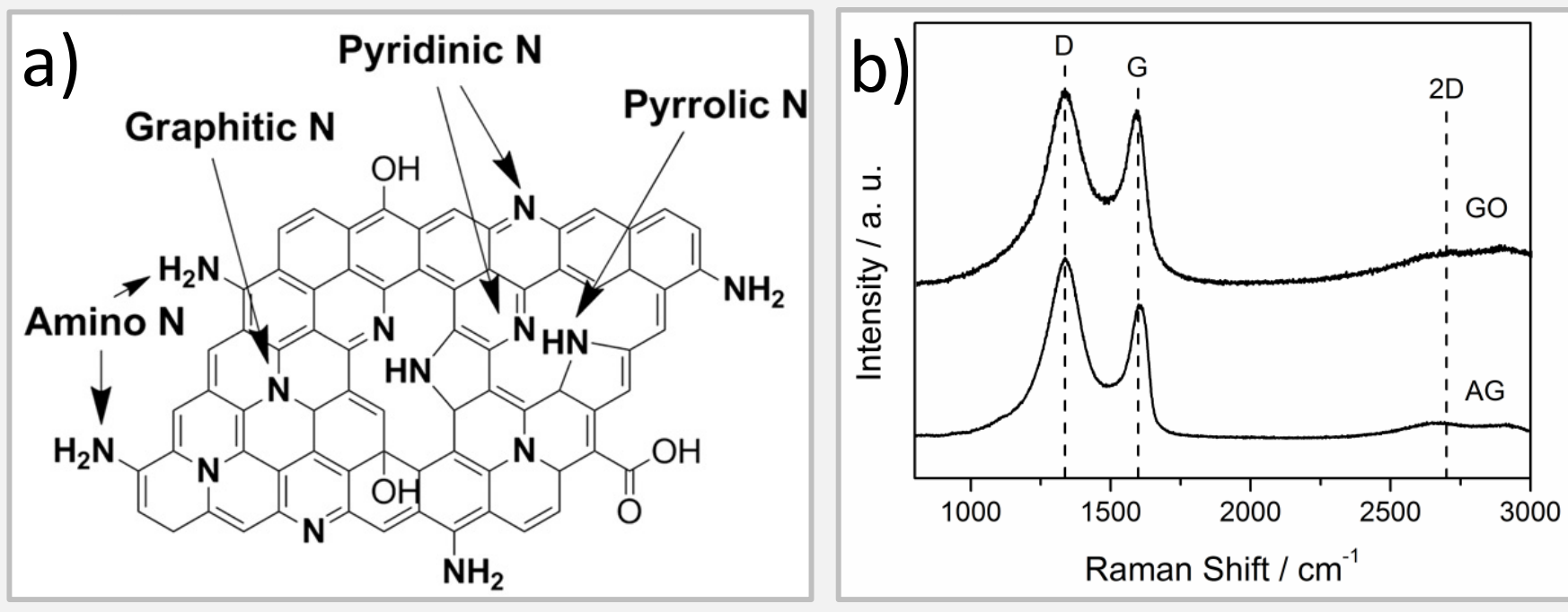

Figure 4. Part a) Schematic representation of amino-functionalized graphene. Part b) Raman spectra of amino-functionalized graphene (bottom) and graphite oxide (top). Reprinted from Nano Energy, 2, C. Zhang, R. Hao, H. Liao, Y. Hou, Synthesis of amino-functionalized graphene as metal-free catalyst and exploration of the roles of various nitrogen states in oxygen reduction reaction, 88-97, Copyright (2013) with permission from Elsevier.

Figure $4 \mathrm{~b}$ shows the Raman spectrum (collected with an excitation $\lambda=632.8 \mathrm{~nm}$ ) of the aminofunctionalised graphene prepared by Zhang et $a l^{8}{ }^{8}$, compared to that of GO. The two spectra are very similar, proving once again the insensitivity of Raman spectroscopy to the surface functionalization.

\subsubsection{Raman spectroscopy of carbon nanotubes (CNTs)}

Single walled carbon nanotubes (SWCNTs), discovered in $1993,{ }^{14}$ can be considered as nanoscale graphene cylinders that are closed at each end by half a fullerene. Multi-walled carbon nanotubes (MWCNTs) contain two or more concentric graphene cylinders. ${ }^{15}$ Depending on the arrangement along the tube of the hexagon rings, SWCNTs can be metallic or semiconducting, ${ }^{16}$ while MWCNTs are expected to be metallic. Raman spectroscopy is one of the most extensively employed tool to characterize CNTs. The tangential modes are the most intense high frequency modes of SWCNTs and give rise to the G band (always around $1600 \mathrm{~cm}^{-1}$ ). When SWCNTs are functionalized, the defect-induced D band in the $1400-1300 \mathrm{~cm}^{-1}$ range becomes more prominent. A dependence on the diameter of the SWCNTs is frequently observed. 
The most characteristic features in the Raman spectrum of SWCNTs are the low frequency 'radial breathing modes' (RBMs) in the $350-150 \mathrm{~cm}^{-1}$ range, which is observed when all the carbon atoms of the tube vibrate radially in phase. The frequency of these vibrational modes depends inversely on the diameter $\mathrm{d}$ of the SWCNTs, and not on the way the SWCNT is rolled up to form a cylinder. In the case of functionalization, the RBMs undergo to a frequency shift. Figure 5 shows typical Raman spectra of SWCNTs collected with two different laser lines, in both the RBMs range (parts a and c) and G and D range (parts $\mathrm{c}$ and $\mathrm{d}$ ). Comparison is set to ozonized SWCNTs. Small nanotubes are preferentially ozonized. Hence, the differences observed between the two spectra can be ascribed to the functionalization of smaller nanotubes. ${ }^{17}$

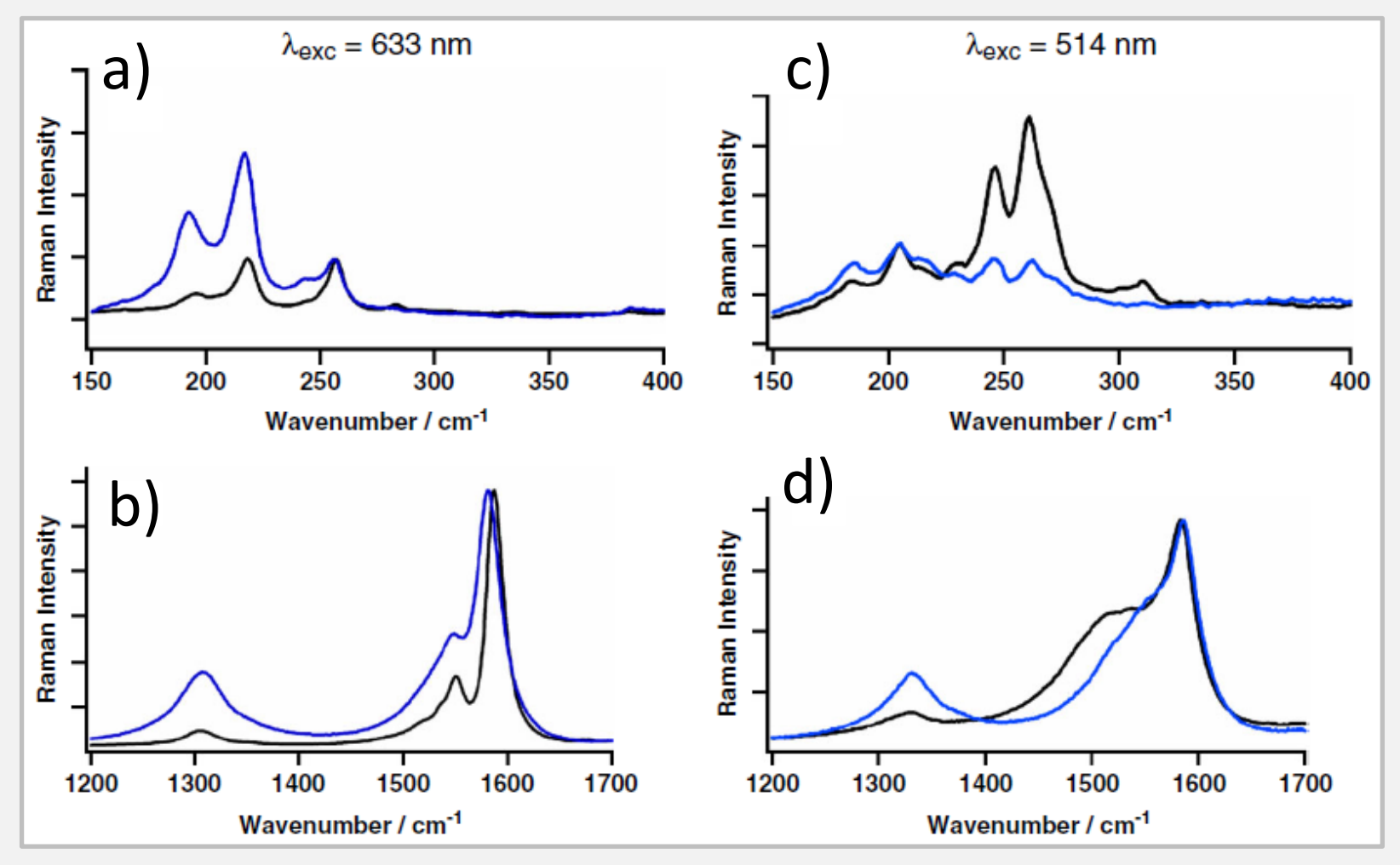

Figure 5. Raman spectra of as such (black) and ozonized (blue) SWCNTs collected with excitation $\lambda=633$ $\mathrm{nm}$ (parts a and b), and $\lambda=514 \mathrm{~nm}$ (parts $\mathrm{c}$ and $\mathrm{d}$ ) in the RBMs range (parts a and c) and $\mathrm{G}$ and D bands range (parts b and d). Reprinted (adapted) with permission from (S. Banerjee, S. S. Wong, Nano Lett., 2004, 4, 1445-1450). Copyright (2004) American Chemical Society.

\subsubsection{Raman spectroscopy of other C-containing materials}

Graphitic carbon nitride $\left(\mathrm{g}-\mathrm{C}_{3} \mathrm{~N}_{4}\right)$ composed by $\mathrm{C}$ and $\mathrm{N}$ elements demonstrated great potential in sustainable processes employing solar energy; furthermore, showing great stability in both very acidic and basic conditions, it could be a good candidate for a wide variety of applications in metal-free catalysis. ${ }^{18} \mathrm{~g}$ - 
$\mathrm{C}_{3} \mathrm{~N}_{4}$ can be obtained by step process starting from dicyandiammide and heating: during such process $\mathrm{NH}_{3}$ molecules are released and condensation occurs forming melamine->melem->melon and finally porous g$\mathrm{C}_{3} \mathrm{~N}_{4}$, according to Figure $6 \mathrm{a}$.
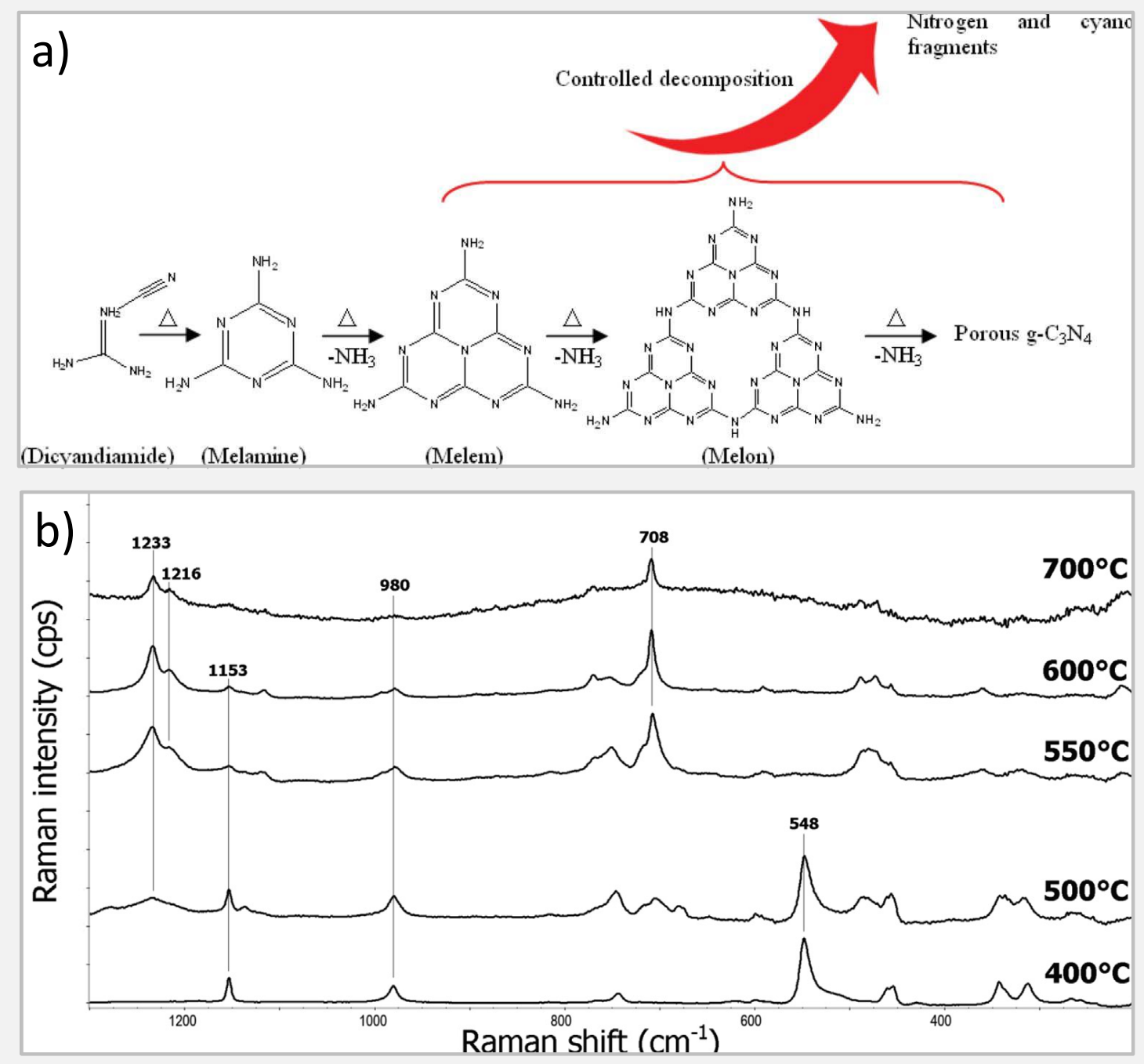

Figure 6. Part a) Reaction processes of porous $\mathrm{g}_{-} \mathrm{C}_{3} \mathrm{~N}_{4}$ during the thermal treatment of dicyandiamide. Reproduced from Ref. ${ }^{18}$ with permission from The Royal Society of Chemistry. Part b) Raman spectra of melamine products obtained at different temperatures. Reprinted from Mater. Chem. Phys., 193, P. Praus, L. Svoboda, M. Ritz, I. Troppová, M. Šihor, K. Kočí, Graphitic carbon nitride: Synthesis, characterization and photocatalytic decomposition of nitrous oxide, 438-446, Copyright (2017) with permission from Elsevier.

Interestingly, Raman spectroscopy can be employed to follow the $\mathrm{g}_{-} \mathrm{C}_{3} \mathrm{~N}_{4}$ formation process, as shown in Figure $6 \mathrm{~b}$ (exciting laser line $780 \mathrm{~nm})^{19}$ The spectral region of $1250-400 \mathrm{~cm}^{-1}$ is typical for skeletal vibrations of nitrogen containing aromatic rings. ${ }^{20}$ Triazine group $^{21}$ is present at all temperatures as demonstrated by the presence of a band falling at $980 \mathrm{~cm}^{-1}$, even if starting from $550{ }^{\circ} \mathrm{C}$ it becomes broader 
and finally hardly recognizable from the background at $700{ }^{\circ} \mathrm{C}$. Melem bands, situated respectively at 1153 $\mathrm{cm}^{-1}$ and $548 \mathrm{~cm}^{-1}$, are both well visible in the $400-500{ }^{\circ} \mathrm{C}$ temperature range, the second one disappearing at higher temperature. Peak attributable to melon product (located at $1233 \mathrm{~cm}^{-1}$ ) starts to appear at $500{ }^{\circ} \mathrm{C}$, becoming even more visible and well defined as temperature increases up to $600{ }^{\circ} \mathrm{C}$. Typical peak of g$\mathrm{C}_{3} \mathrm{~N}_{4}$, located at $708 \mathrm{~cm}^{-1},{ }^{22}$ is well visible in the $550-700{ }^{\circ} \mathrm{C}$ temperature range.

\subsection{IR spectroscopy applied to carbons: principles, problems and solutions}

IR spectroscopy relies on the use of photons in the IR region (usually in the Mid-IR interval, i.e. 400 $4000 \mathrm{~cm}^{-1}$ ) to excite atomic vibrations. In order for a vibrational mode in a molecule (or a molecular fragment) to be IR active, it must be associated with changes in the dipole moment. It derives that not all the vibrational modes of a molecule are IR active, but only those that satisfy the dipole selection rule. Moreover, according to the Lambert-Beer law, the intensity of an IR absorption band generally depends on the concentration of the corresponding species, but also on the molar extinction coefficient, which is not constant along the energy interval and is a function of the type of vibration. Hence, IR spectroscopy can be used for quantitative evaluation of the absorbing species only when the extinction coefficient has been previously determined.

As far as carbonaceous materials are concerned, the $v(\mathrm{C}-\mathrm{C})$ vibrational modes of conjugated double bonds in graphitic $\mathrm{sp}^{2}$ domains are usually very weak in IR (opposite to what observed in Raman), because they are not associated with a change in the dipole moment. These vibrations can be clearly observed in the IR spectrum of a carbon only in the presence of defects (surface terminations, heteroatoms, functional groups, radical carbon species and others), which are responsible for an increase in the dipole moment associated with the ring vibrations. ${ }^{23-28}$ This is well exemplified by looking at the Fourier transform (FT)-IR spectrum of graphite and grounded graphite, reported in the early 1970s (Figure 7a). ${ }^{29}$ The FTIR spectrum of pristine graphite is completely flat, although weak bands may appear that can be assigned to adsorbed water molecules. ${ }^{30}$ The FT-IR spectrum of graphite could be observed only by means of an exhaustive and efficient grinding, i.e. when graphite loses the long-range structure. The $v(C=C)$ vibrations of the $\mathrm{sp}^{2}$ domains are observed around $\sim 1587 \mathrm{~cm}^{-1}$ and $\sim 1362 \mathrm{~cm}^{-1}$, very close to the Raman fingerprints for the crystalline graphite.

Two important consequences derive from the above mentioned statements:

1) IR spectroscopy brings only indirect information on the bulk properties of carbon-based materials, while it conveys direct information on the surface species, including the $\mathrm{C}-\mathrm{H}$ groups at the periphery of the $\mathrm{sp}^{2}$ clusters (usually characterized by weak absorptions) and the functional groups containing heteroatoms (such as oxygen, nitrogen, etc.). The vibrational modes associated with the functional groups are usually characterized by very intense extinction coefficients. This is the reason why IR spectroscopy has been 
extensively used to investigate the surface species in different carbon-based materials, including activated carbons, ${ }^{27,28,31,32}$ carbon blacks,${ }^{33}$ char, ${ }^{34,35}$ coal, ${ }^{36}$ graphite, ${ }^{29}$ carbon fibres,${ }^{37}$ carbons films, ${ }^{38}$ nano-carbons and other systems. ${ }^{30}$ In this respect, IR spectroscopy is perfectly complementary to Raman spectroscopy.

2) The quantitative determination of the surface species on carbons is not trivial, since the overall intensity of the IR spectrum is greatly affected by the presence of both chemical and physical defects, which enhance the dipole moment associated with the rings vibrations.

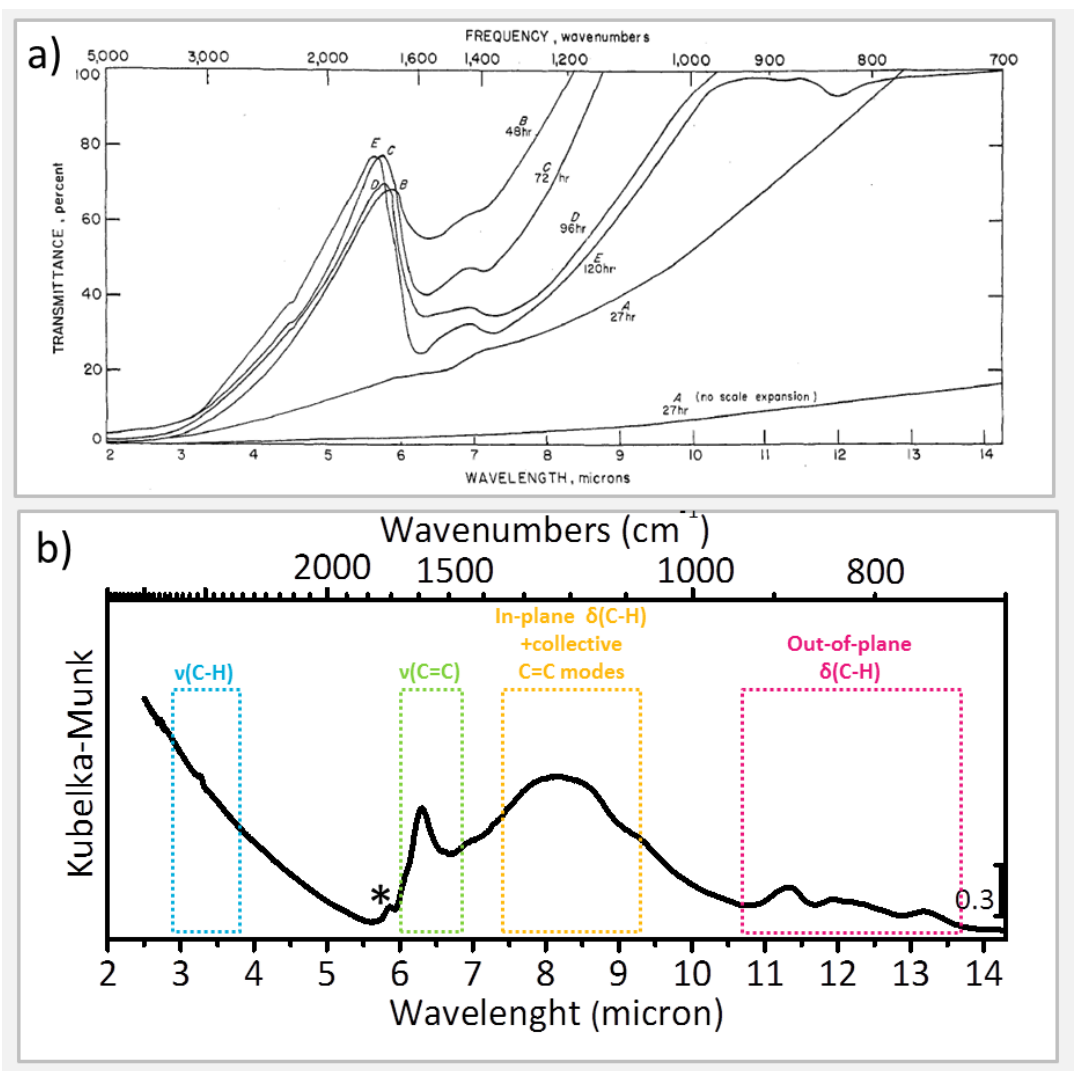

Figure 7. Part a) IR spectrum (collected in transmission mode) of ball-milled graphite. The ball-milling time is reported for each spectrum. Reprinted (adapted) with permission from (R. A. Friedel, G. L. Carlson, J. Phys. Chem., 1971, 75, 1149-1151). Copyright (1971) American Chemical Society. Part b) IR spectrum (collected in DRIFT mode and reported in Kubelka-Munk units) of a chemically activated carbon and assignment of the main absorption bands. Unpublished spectrum.

Despite the large literature in this field, very often the IR spectra of carbon-based materials are characterized by undesirable spectral artefacts or distortions which complicate the data interpretation, especially when collected in the conventional transmission mode. This is mainly due to the fact that the electronic structure of foremost carbon materials results in a wide absorption through the visible and the infrared regions. As a consequence, “dark carbons" generally have a poor transmission and uneven light 
scattering. Dilution in $\mathrm{KBr}$ does not help so much, since the sample preparation is time-consuming and the grinding conditions affect the IR spectrum. Moreover, it has been demonstrated that $\mathrm{KBr}$ may alter the surface properties of carbon-based materials. At least part of the problem can be avoided by performing the measurements in diffuse reflectance mode (DRIFT), whereby the scattered (rather than transmitted) light is collected. Figure 8 shows the two most employed methods for collecting the IR spectrum of a carbon-based material.

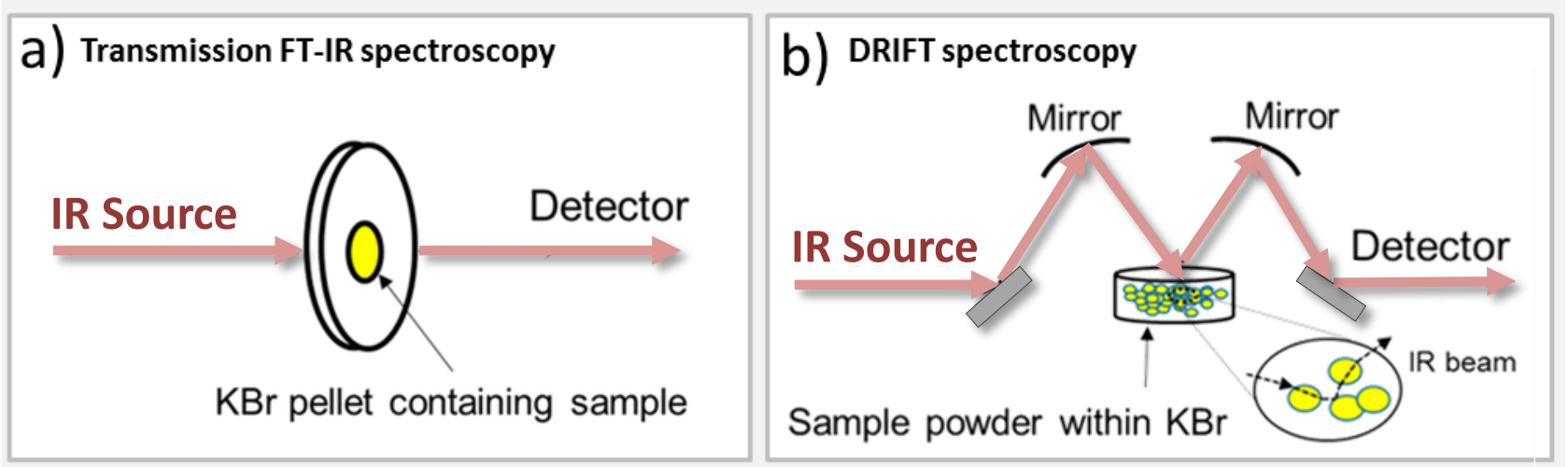

Figure 8. Schematic representation of the most common instrumental set-ups available for the characterization of carbon-based materials by IR spectroscopy. Part a) Transmission mode; Part b) DRIFT mode.

\subsubsection{FT-IR spectroscopy of activated carbons}

A typical DRIFT spectrum of a carbon of wood origin chemically activated is shown in Figure $7 \mathrm{~b}$, along with the assignment of the main absorption bands. The spectrum is dominated by a narrow band around $1600 \mathrm{~cm}^{-1}$, which is due to the $v(\mathrm{C}=\mathrm{C})$ vibrational modes of conjugated $\mathrm{sp}^{2}$ bonds belonging to graphitic islands $^{26-28,39}$ and by a very broad absorption in the $1300-1000 \mathrm{~cm}^{-1}$ region due to the overlapped contribution of in-plane $\delta(\mathrm{C}-\mathrm{H})$ modes and of the collective skeletal C-C vibrational modes. ${ }^{26-28}$ These two bands are very similar to those observed in the spectrum of intensively grinded graphite (Figure 7Two important consequences derive from the above mentioned statements:

1) IR spectroscopy brings only indirect information on the bulk properties of carbon-based materials, while it conveys direct information on the surface species, including the $\mathrm{C}-\mathrm{H}$ groups at the periphery of the $\mathrm{sp}^{2}$ clusters (usually characterized by weak absorptions) and the functional groups containing heteroatoms (such as oxygen, nitrogen, etc.). The vibrational modes associated with the functional groups are usually characterized by very intense extinction coefficients. This is the reason why IR spectroscopy has been extensively used to investigate the surface species in different carbon-based materials, including activated carbons, ${ }^{27,28,31,32}$ carbon blacks, ${ }^{33}$ char, ${ }^{34,35}$ coal,${ }^{36}$ graphite, ${ }^{29}$ carbon fibres,${ }^{37}$ carbons films, ${ }^{38}$ nano-carbons 
and other systems. ${ }^{30}$ In this respect, IR spectroscopy is perfectly complementary to Raman spectroscopy.

2) The quantitative determination of the surface species on carbons is not trivial, since the overall intensity of the IR spectrum is greatly affected by the presence of both chemical and physical defects, which enhance the dipole moment associated with the rings vibrations.

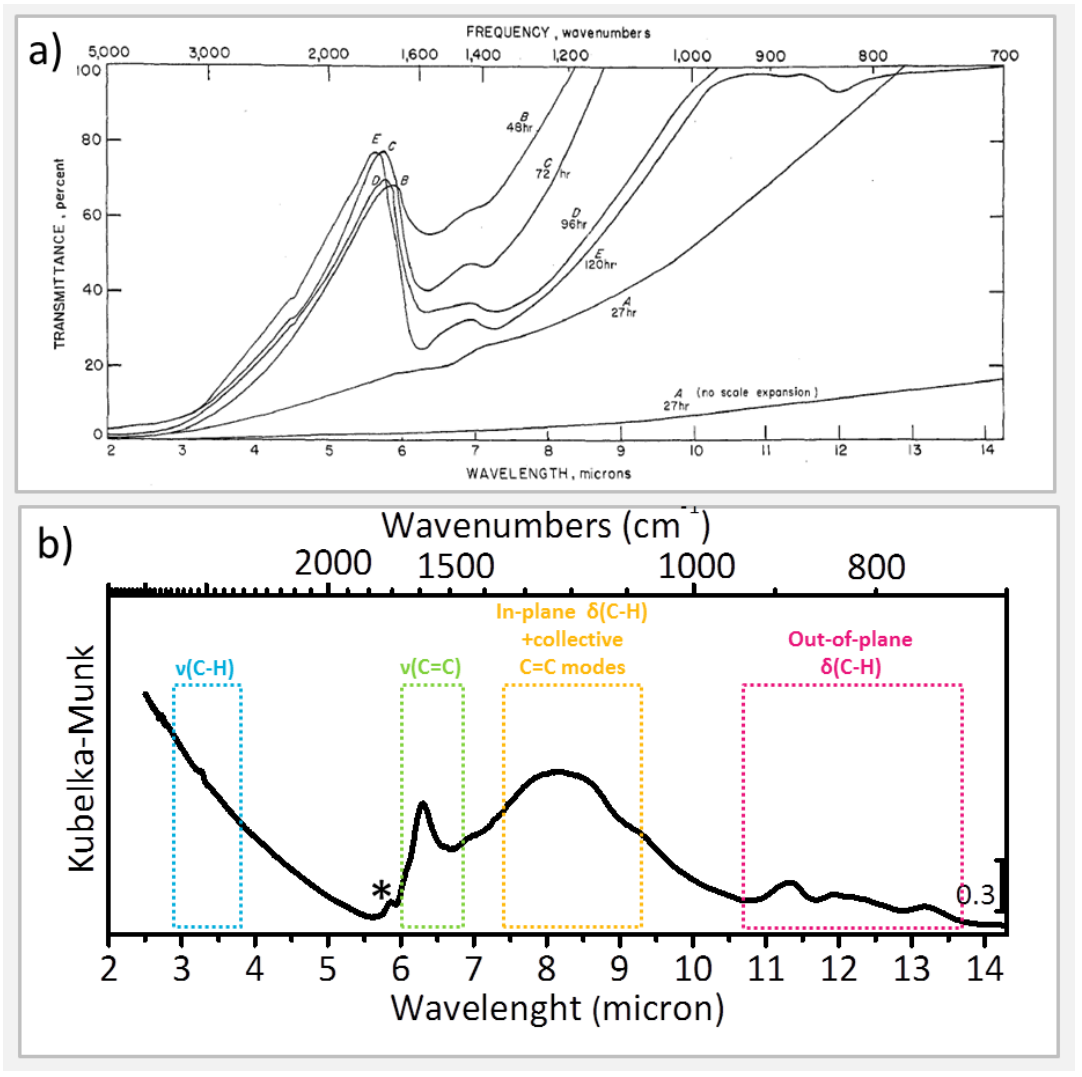

Figure 7. Part a) IR spectrum (collected in transmission mode) of ball-milled graphite. The ball-milling time is reported for each spectrum. Reprinted (adapted) with permission from (R. A. Friedel, G. L. Carlson, J. Phys. Chem., 1971, 75, 1149-1151). Copyright (1971) American Chemical Society. Part b) IR spectrum (collected in DRIFT mode and reported in Kubelka-Munk units) of a chemically activated carbon and assignment of the main absorption bands. Unpublished spectrum.

a). ${ }^{29}$ Differently from graphite, the spectrum of the chemically activated carbon shows also a weak band around $1710 \mathrm{~cm}^{-1}$ (*Figure $7 \mathrm{~b}$ ), assigned to $v(\mathrm{C}=\mathrm{O})$ vibrations of carboxyl and carbonyl groups, and a series of bands in the $900-750 \mathrm{~cm}^{-1}$ range, which are assigned to the out-of-plane vibrations of $\mathrm{C}-\mathrm{H}$ species at the borders of the $\mathrm{sp}^{2}$ domains, differing in the number of adjacent $\mathrm{H}$ atoms. ${ }^{27,28} \mathrm{~A}$ more extended discussion on this spectral region will be done in Section 4.4 

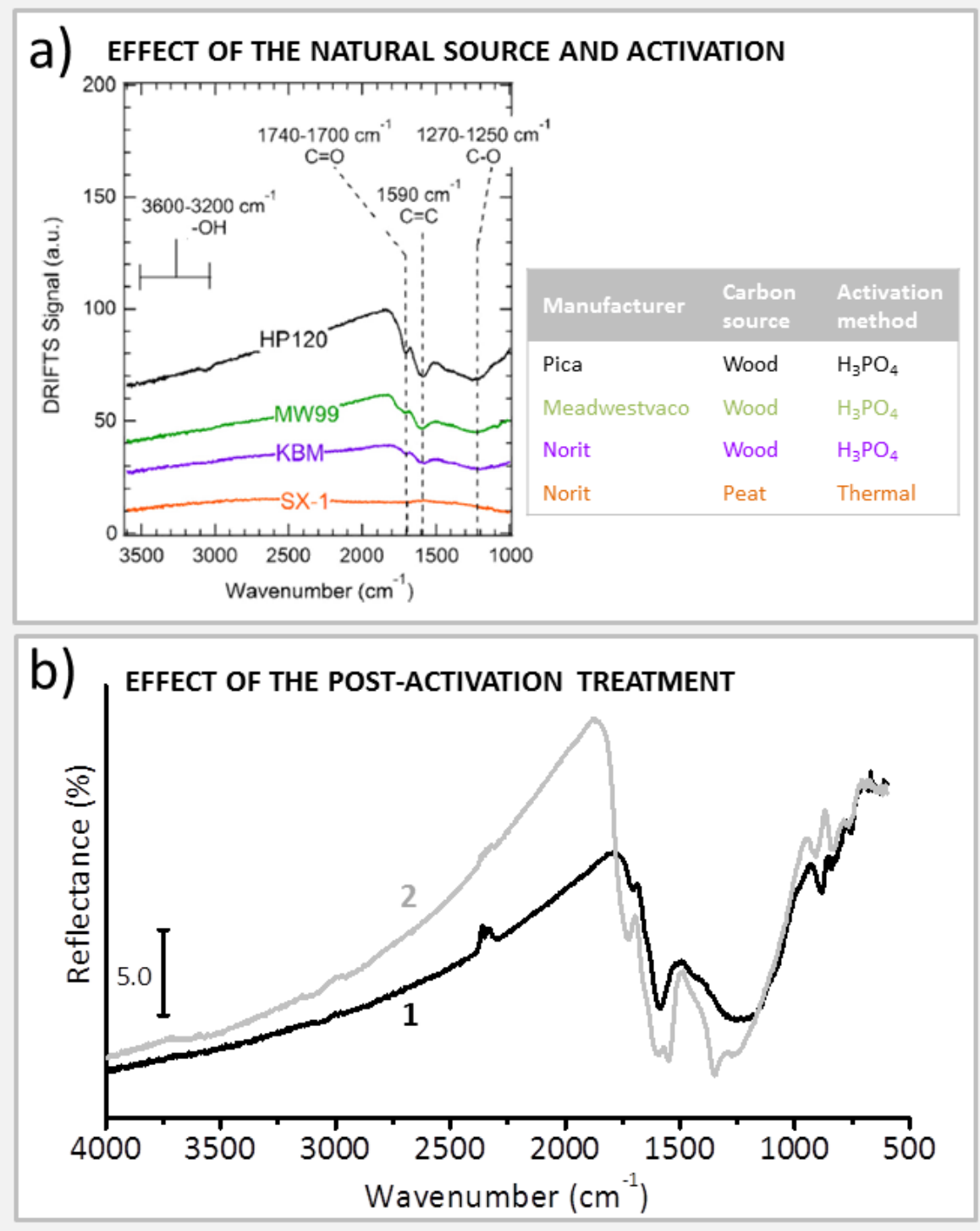

Figure 9. Part a) DRIFT spectra of several carbons having a different origin (wood or peat) and activated either in phosphoric acid (chemical activation) or in steam (physical activation). The assignment of the main absorption bands is also reported. Reprinted from Fuel, 163, M. T. Timko, J. A. Wang, J. Burgess, P. Kracke, L. Gonzalez, C. Jaye, D. A. Fischer, Roles of surface chemistry and structural defects of activated carbons in the oxidative desulfurization of benzothiophenes, 223-231, Copyright (2016) with permission from Elsevier. Part b) DRIFT spectrum of a chemically activated carbon (wood origin, spectrum 1) compared to that of the same sample subjected to an oxidative treatment (conc. $\mathrm{HNO}_{3}$, room temperature, spectrum 2). Unpublished spectra.

Not all the activated carbons display a DRIFT spectrum so rich of details as that reported in Figure 7b. The natural raw material (e.g. wood, coconut shell, peat), the type of activation (physical or chemical) and the eventual post-activation treatments are all factors affecting the intensity of the DRIFT spectrum, ${ }^{27,28,40}$ as 
illustrated in Figure 9a
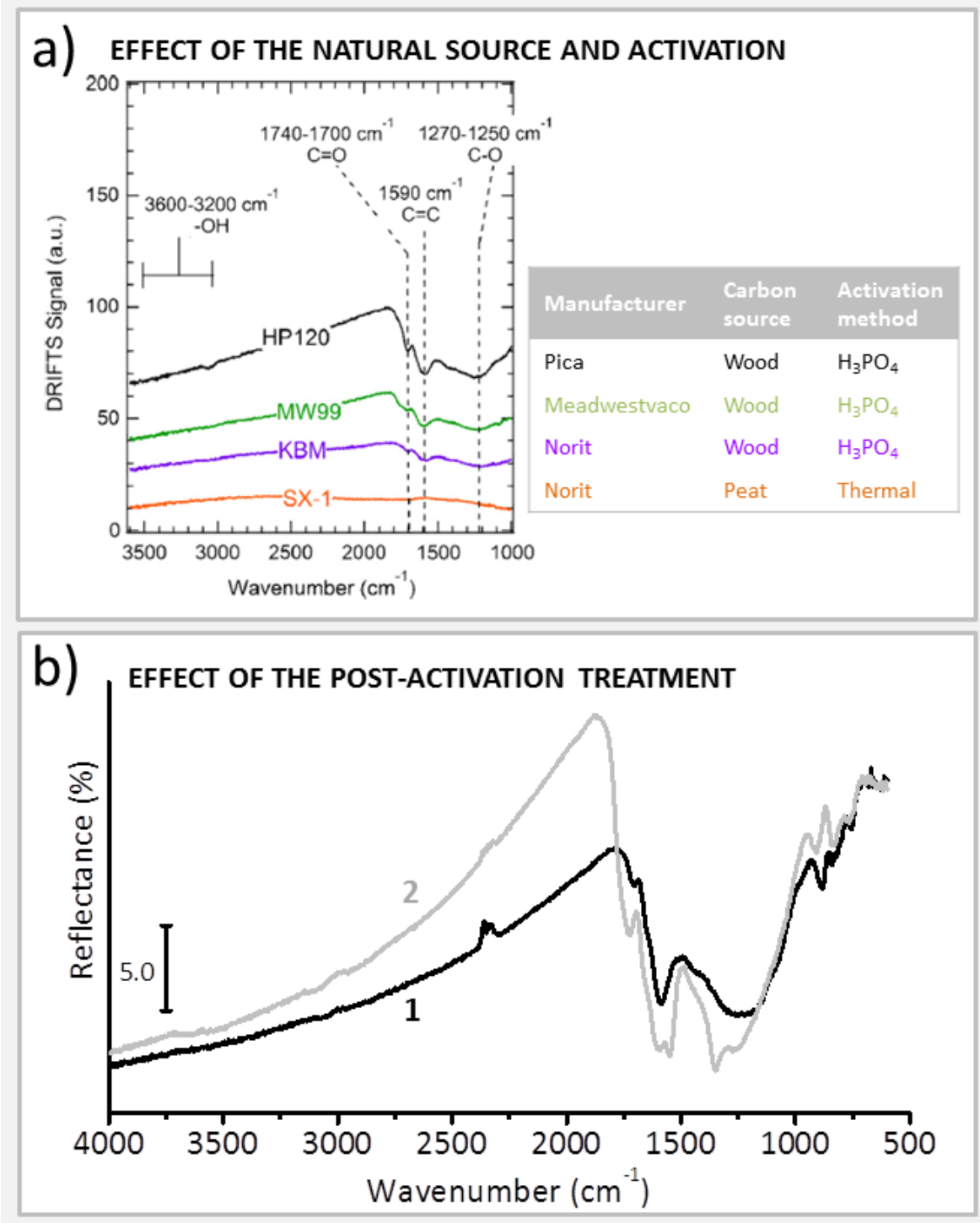

Figure 9. Part a) DRIFT spectra of several carbons having a different origin (wood or peat) and activated either in phosphoric acid (chemical activation) or in steam (physical activation). The assignment of the main absorption bands is also reported. Reprinted from Fuel, 163, M. T. Timko, J. A. Wang, J. Burgess, P. Kracke, L. Gonzalez, C. Jaye, D. A. Fischer, Roles of surface chemistry and structural defects of activated carbons in the oxidative desulfurization of benzothiophenes, 223-231, Copyright (2016) with permission from Elsevier. Part b) DRIFT spectrum of a chemically activated carbon (wood origin, spectrum 1) compared to that of the same sample subjected to an oxidative treatment (conc. $\mathrm{HNO}_{3}$, room temperature, spectrum 2). Unpublished spectra.

. Generally speaking, carbons of peat origin and physically activated (i.e. by steam) display a very weak DRIFT spectrum where the absorption bands are hardly recognizable. Carbons of wood origin chemically 
activated usually show an intense DRIFT spectrum, indicating less regular $\mathrm{sp}^{2}$ domains, with several bands ascribable to oxygen-containing functional groups.

The DRIFT spectrum of an activated carbon greatly changes as a consequence of post-activation treatments. Figure 9
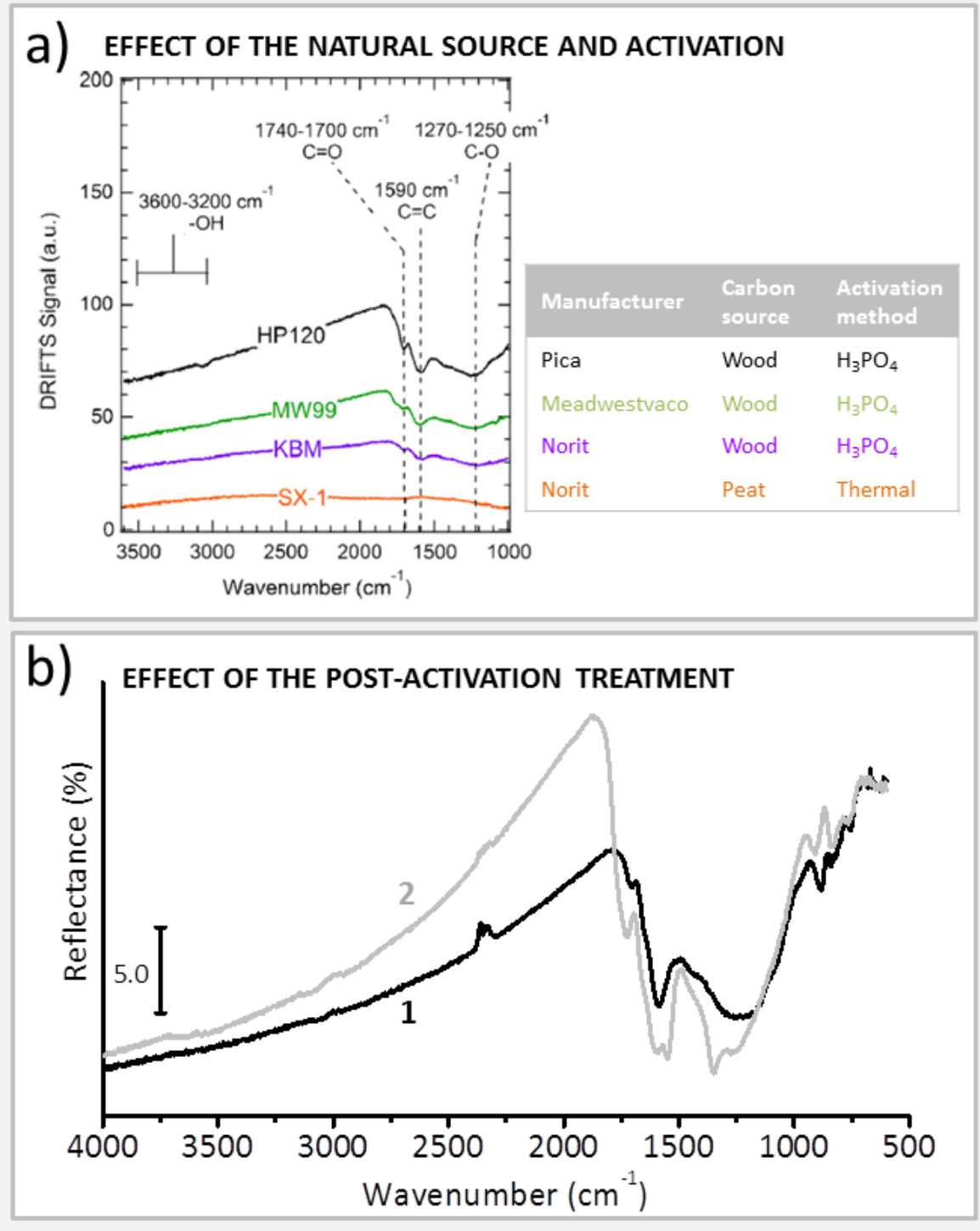

Figure 9. Part a) DRIFT spectra of several carbons having a different origin (wood or peat) and activated either in phosphoric acid (chemical activation) or in steam (physical activation). The assignment of the main absorption bands is also reported. Reprinted from Fuel, 163, M. T. Timko, J. A. Wang, J. Burgess, P. Kracke, L. Gonzalez, C. Jaye, D. A. Fischer, Roles of surface chemistry and structural defects of activated carbons in the oxidative desulfurization of benzothiophenes, 223-231, Copyright (2016) with permission from Elsevier. Part b) DRIFT spectrum of a chemically activated carbon (wood origin, spectrum 1) compared to that of the same sample subjected to an oxidative treatment (conc. $\mathrm{HNO}_{3}$, room temperature, spectrum 2). Unpublished spectra. 
b shows the effect of an oxidative treatment (room temperature, concentrated $\mathrm{HNO}_{3}$ ) on the DRIFT spectrum of a chemically activated carbon of wood origin. The whole spectrum is almost doubled in intensity, which is a direct consequence of the increased dipole moment associated with the $\mathrm{sp}^{2}$ ring vibrations, as expected in the presence of oxygenated electron-withdrawing groups. In addition, new absorption bands are observed, denoting the formation of new functional groups:

1) A first group of bands appears in the $v(\mathrm{C}=\mathrm{O})$ vibrational region, with absorption maxima at 1766 and $1726 \mathrm{~cm}^{-1}$, due to acidic functionalities. A precise assignment of these bands is not straightforward since the $v(\mathrm{C}=\mathrm{O})$ vibrations of acid groups in an aromatic ring structure are affected by the presence of different peripheral groups in close proximity. Hence, the same band can be potentially ascribed to two different groups, or to the same one but in two different environments. ${ }^{27,28,41,42}$

2) A second group of bands appears at $1550 \mathrm{~cm}^{-1}$ and $1350 \mathrm{~cm}^{-1}$, which are assigned to the asymmetric and symmetric stretching modes of carboxylate groups. ${ }^{27}$ The formation of carboxylates in acidic conditions is made possible because of the extended conjugation of the $\pi$ electrons, which allows a redistribution of the electron density within the graphene layers. It has been demonstrated that for aromatic acids both inductive effects (i.e. the influence of neighbours on the acidic strength of carboxylic groups) and resonance effects contribute to enhancing the stability of carboxylate anions. ${ }^{31}$ This phenomenon has been recently discussed $^{43,44}$ as responsible for the partial graphitization of activated carbons by $\mathrm{HNO}_{3}$ treatments.

3) Finally, also the $900-750 \mathrm{~cm}^{-1}$ region, due to terminal $\mathrm{C}-\mathrm{H}$ groups is affected (see Section 4.3 for further discussion).

In this context, it is relevant to notice the role played by the activating agents $\left(\mathrm{ZnCl}_{2}, \mathrm{H}_{3} \mathrm{PO}_{4}\right.$, etc. $),{ }^{45}$ which are often responsible for the formation of defective regions characterized by the presence of heteroatoms and dopants $(\mathrm{B}, \mathrm{N}, \mathrm{O}, \mathrm{P}, \mathrm{S}) .^{46,47}$ The presence of dangling groups, hydrogen saturation and polar groups has been widely demonstrated to alter the local density of the $\pi$-electrons, thus increasing the chemical reactivity. For carbons activated with $\mathrm{H}_{3} \mathrm{PO}_{4},{ }_{t}$ absorption bands in the $1300-1000 \mathrm{~cm}^{-1}$ range have been sometimes attributed to phosphorous containing groups $\left(\mathrm{P}=\mathrm{O}, \mathrm{P}-\mathrm{O}-\mathrm{P}, \mathrm{P}=\mathrm{OOH}, \mathrm{P}-\mathrm{O}-\mathrm{C}\right.$ and ionized $\mathrm{P}^{+}-\mathrm{O}^{-}$ ).${ }^{48}$ Nitrogen-doped porous carbons, which have been demonstrated very effective in environmental issues (fuel cells, $\mathrm{CO}_{2}$ capture and segregation), have been reported to show absorption bands at $1263 \mathrm{~cm}^{-1}$ and at $3300 \mathrm{~cm}^{-1}$ associated with $v(\mathrm{C}-\mathrm{N})$ and $v(\mathrm{NH})$, respectively. ${ }^{49}$

\subsubsection{FT-IR spectroscopy of GO, RGO, and doped GO}

The exfoliation process on graphite gives graphene, which is a flat crystalline single-atomic-layer of $\mathrm{sp}^{2}$ carbon atoms within a two-dimensional hexagonal honeycomb lattice. As for graphite, no significant absorption bands are observed in the FTIR spectrum of graphene. ${ }^{50,51,52}$ In the graphene technology, 
graphite is employed to synthesise GO, which is a chemically functionalized material consisting of oxygenrich carbonaceous layers, where the graphite structure is maintained. On the contrary, the interlayer distance is increased due to the presence of oxygen-containing functional groups. GO is composed by both $\mathrm{sp}^{3}-\mathrm{sp}^{2}$-hybridized carbons, with hydroxyl and ether/epoxy groups arranged on the top and bottom of the surfaces, and with carbonyl and carboxyl groups in the sheet and on the edges, respectively. Such functional groups can be detected by FT-IR spectroscopy. Typical absorption bands are observed at 1230$1215 \mathrm{~cm}^{-1}$ (C-O bonds), at $1120-1110 \mathrm{~cm}^{-1}$ (epoxy species), at $1415 \mathrm{~cm}^{-1}, 1160 \mathrm{~cm}^{-1}$ (carbonyl or carboxyl groups) and at 1080-1040 $\mathrm{cm}^{-1}$ (alkoxy or epoxy moieties). These spectroscopic features indicates that the extended conjugated $\pi$-orbital system of the pristine graphite is destroyed and that $\mathrm{C}=\mathrm{O}$ groups, with stretching mode appearing at $1740-1720 \mathrm{~cm}^{-1}$, are introduced into the graphite pristine framework.

The GO oxidation degree can be evaluated by the increase in intensity of the $v(\mathrm{C}=\mathrm{O})$ band along with the decrease in intensity of other $\mathrm{C}-\mathrm{O}$ peaks due to $\mathrm{C}-\mathrm{OH}$ and/or $\mathrm{O}-\mathrm{O}-\mathrm{C}$ bonds. Adsorbed water can be detected by checking the presence of an absorption band around $3450 \mathrm{~cm}^{-1}$ due to the interaction with $\mathrm{OH}$ groups, which renders hydrophilic the GO. Generally, the band at $1640-1620 \mathrm{~cm}^{-1}$, due to the presence of $\mathrm{OH}$ groups is overlapped with the in-plane vibrations of the skeletal $\mathrm{C}=\mathrm{C}$ band related to the hexagonal aromatic rings of graphene sheet or to the residual $\mathrm{sp}^{2}$ character after oxidation of the graphitic network. The vibrational stretching mode of aryl $\mathrm{C}=\mathrm{C}$ is observed at $1420 \mathrm{~cm}^{-1} .53,13$

GO is used to prepare either chemically modified graphene or reduced graphene oxide (RGO) by simply heating or by chemical reduction. These processes lead to the decrease in intensity of the absorption bands associated to $\mathrm{C}=\mathrm{O}, \mathrm{C}-\mathrm{O}$ and $\mathrm{C}-\mathrm{H}$ groups, which are totally depleted upon deoxygenation. ${ }^{12}$ Therefore, differently from what happens for Raman spectroscopy (see paragraph 4.1.3), the presence of a band centred in the $1585-1565 \mathrm{~cm}^{-1}$ range and related to the $\mathrm{C}=\mathrm{C}$ aromatic group of graphene sheet is expected when GO is completely reduced at temperature below $1100{ }^{\circ} \mathrm{C}$. On the contrary, an increase in intensity of the bands observed at $2950-2850 \mathrm{~cm}^{-1}$ and related to $\mathrm{C}-\mathrm{H}$ bonds stretching is observed when chemical reduction is performed. ${ }^{54}$

$\mathrm{N}$-doped GO can be obtained by heating GO in the presence of different amounts of N-containing molecules, such as ammonium nitrate, ${ }^{55}$ urea, ${ }^{56}$ thiourea, ammonium dicynamide, cynamide, melamine,${ }^{57}$ as well aminopropyltrimethoxysilane. ${ }^{58}$ Among these, melamine gives interesting results, due to the uniform distribution of $\mathrm{N}^{59}$ With this in mind, N-doped graphene can be effectively characterised by FT-IR spectroscopy, which reveals the presence of bands at 1244, 1321 and $1427 \mathrm{~cm}^{-1}$ due to aromatic $\mathrm{C}=\mathrm{N}$ stretching mode and of one band centred at $807 \mathrm{~cm}^{-1}$, due to the triazine ring mode. These absorption bands increase in intensity and blue shift with increasing the $\mathrm{N}$ content. ${ }^{57}$ It is worth of note that FT-IR spectroscopy can be helpful to investigate simultaneously the effectiveness of the $\mathrm{N}$ doping into the graphene framework and the reduction of the O-containing species in GO. ${ }^{55,56}$ After reduction, the band at 
$3411 \mathrm{~cm}^{-1}$ attributed to the stretching vibration of hydroxyl groups decreases in intensity and a weak band at $1732 \mathrm{~cm}^{-1}$, assigned to the $\mathrm{C}=\mathrm{O}$ stretching vibration in conjugated graphene, indicates the presence of residual $\mathrm{C}=\mathrm{O}$ groups surviving after the reduction process. Most important is the red shift of the band corresponding to the in-plane vibration of $\mathrm{C}=\mathrm{C}$ (from 1624 to $1556 \mathrm{~cm}^{-1}$ ), as a consequence of the superposition of the absorptions related to $\mathrm{C}=\mathrm{C}$ and $\mathrm{C}=\mathrm{N}$, giving evidence of effective embedding of $\mathrm{N}$ containing groups. ${ }^{60,61}$

Beside nitrogen, also boron and fluorine can be used to dope graphene. Boron-doped 2D carbons with photoluminescence properties, obtained by hot-filament CVD technique, have been recently reported by Wang et al. ${ }^{62}$. An absorption band at about $790 \mathrm{~cm}^{-1}$ in the IR spectrum, associated with the C-B bonds, provides evidence of the boron incorporation in the material. Halogenated graphenes, such as fluorographene and chlorographene, usually exhibit much stronger IR bands owing to a higher transparency and show prominent absorption features at $\sim 1260 \mathrm{~cm}^{-1}$ or at $\sim 1110 \mathrm{~cm}^{-1}$, corresponding to $v(\mathrm{C}-\mathrm{F})$ or $v(\mathrm{C}$ $\mathrm{Cl}$ ), respectively. FT-IR studies conducted at increasing fluorination time have revealed an absorption band at $1112 \mathrm{~cm}^{-1}$, assigned to "semi-ionic" C-F, which gradually disappears, giving rise to a strong band at 1211 $\mathrm{cm}^{-1}$ due ti the covalent C-F bonding. Features at $600 \mathrm{~cm}^{-1}$ or at $745 \mathrm{~cm}^{-1}$ are representative of the $v(\mathrm{C}-\mathrm{Br})$ and $v(\mathrm{C}-\mathrm{I})$ bonds. ${ }^{63}$

\subsubsection{FT-IR spectroscopy of CNTs}

Both SWCNTs and MWCNTs have been extensively investigated by IR spectroscopy. In this regard, IR active modes of CNTs can be found in the $1580-1530 \mathrm{~cm}^{-1}$ range ( $\mathrm{sp}^{2}$ carbon) and $1200-1100 \mathrm{~cm}^{-1}$ interval (more disordered $\mathrm{sp}^{3}$ carbon). These skeletal vibrational modes depend on the CNT symmetry and their expected wavenumbers in the IR spectrum are influenced by the nanotube diameters $(\sim 0.4-2.0 \mathrm{~nm}$ for SWNTs and $\sim 5-1000 \mathrm{~nm}$ for MWNTs). This explains why the corresponding absorption bands are quite broad. For MWCNTs the broadness is the result of the presence of multiple concentric tubes having a different diameter, while for SWCNTs the broadness of the $v(C=C)$ absorption band can be explained by the polydispersity of the nanotubes. ${ }^{30}$ Additional IR bands around $2800-3000 \mathrm{~cm}^{-1}$ are due to the $v\left(\mathrm{CH}_{\mathrm{x}}\right)$ modes. ${ }^{64}$

The purification, functionalization and doping of CNTs require a strong chemistry, involving the use of mineral acids, oxidizing agents, ${ }^{65}$ cavitation and microwave treatments ${ }^{66}$ or high temperature conditions. These treatments are often required for doping or co-doping CNTs with heteroatoms (i.e. B, N, O, S, I). in this way the catalytic activity of CNTs can be enhanced, for a wide range of reactions including ORR (oxygen reduction reaction), OER (oxygen evolution reaction) and HER (hydrogen evolution reaction). ${ }^{47}$ It is believed that the doping-induced electron modulation at defective edges is responsible for the high catalytic activity of doped CNTs. ${ }^{46}$ Generally speaking, the effects of the doping on a single nanotube are 
qualitatively and quantitatively very difficult to be determined. These difficulties mainly arise from the intrinsic properties of nanotubes (i.e. sample heterogeneity, bundling), impurities and dopant concentrations (even low). The FT-IR spectra of functionalized/doped CNTs may show new absorption bands due to the presence of oxygen rich functional groups formed during the oxidation processes, such as $\mathrm{C}=\mathrm{O}$ or $-\mathrm{OH}$ (absorption bands located at about $1800-1700 \mathrm{~cm}^{-1}$ and at $3200-3600 \mathrm{~cm}^{-1}$, respectively), which are attached to the tube outer-wall or to their open endings. ${ }^{67}$ Furthermore, a presence of a band located at about $1560-1630 \mathrm{~cm}^{-1}$ may be attributed to the interaction of $\mathrm{C}=\mathrm{C}$ conjugation with $\mathrm{C}=\mathrm{O}$ groups at the surface. Nitrogen-doped CNTs can show bands at $1375 \mathrm{~cm}^{-1}(\mathrm{~N}-\mathrm{N}), 2200 \mathrm{~cm}^{-1}$ (N-C) bonds, ${ }^{68}$ while for I- or Br-doped CNTs a band around $600-650 \mathrm{~cm}^{-1}$ or at $580-590 \mathrm{~cm}^{-1}$ can be associated with C-I and CBr bonds, respectively. ${ }^{69,70}$ As for doping of CNTs with boron species, Preston et al. ${ }^{71}$ report the FT-IR spectra of B-(O)-doped few walled CNTs, showing characteristic bands at $1024 \mathrm{~cm}^{-1}$ (B-O-C bend.), 1196 $\mathrm{cm}^{-1}$ (B-O bend.) and $1407 \mathrm{~cm}^{-1}$ (B-O stretch.).

\subsubsection{FT-IR spectroscopy of fullerenes}

Fullerenes are molecules having a closed cage structure exclusively formed by $\mathrm{sp}^{2}$-hybridized $\mathrm{C}$ atoms. Each carbon is bonded by van der Waals interaction to 3 neighbours, having 12 pentagons and a variable number of hexagons, which leads to the existence of molecules with different shapes, such as spheres, ellipsoids, tubes, etc., and with different sizes, depending on the number of $\mathrm{C}$ atoms, going from buckyballs to giant fullerenes. The most popular and the most symmetric molecules are the spherical C60 fullerenes with the most stable molecular structure composed of 60 carbon atoms, 12 pentagons and 20 hexagons, with an icosahedral symmetry where all the rings are fused and all the double bonds are conjugated in a soccer-ball type arrangement. The C60 molecule acts as a deficient electron alkene and readily reacts with electron rich species. Theoretically, the C60 fullerene molecule has $3 \mathrm{~N}-6=174$ vibrational degrees of freedom but, due to the high symmetry of the molecules, only 4 modes are IR-active. ${ }^{30}$ Indeed, C60 molecule shows a very simple FT-IR spectrum with only four characteristic peaks at about $1428 \mathrm{~cm}^{-1}, 1182$ $\mathrm{cm}^{-1}$ associated with a tangential motion of the carbon atoms, $576 \mathrm{~cm}^{-1}$ and $527 \mathrm{~cm}^{-1}$ from a primarily radial motion of the carbon atoms. ${ }^{72}$

For fullerene C60 nanotubes and fullerene dimers, the FT-IR spectra are the same as for the pristine C60, confirming that the FNTs or dimers are composed of C60 molecules. Modification of the surface in order to add epoxides groups to the fullerene cage, for example for obtaining fullerene epoxides, leads to a shift of the main absorption bands to lower wavenumbers and to the appearance of a new band assigned to epoxy groups $\left(1140 \mathrm{~cm}^{-1}\right)$. The $\mathrm{C} 60$ characteristic bands are maintained also for fullerene dimers oxides, indicating that the fullerene cages are intact in these dimers. In addition, new bands appear that may be assigned to various intra-cage vibrations due to dimerisation and epoxy groups. ${ }^{73}$ In the presence of free 
chlorine and UVA irradiation, extensive oxidation of nC60 clusters occurs, ${ }^{74}$ as indicated by the relevant increase in intensity of the bands at about $1700 \mathrm{~cm}^{-1}$ (due to the presence of carbonyl groups), at $1400 \mathrm{~cm}^{-1}$ (assigned to $\mathrm{C}-\mathrm{OH}$ in-plane bending), and at $1100 \mathrm{~cm}^{-1}$ (C-O stretching mode) ${ }^{75,76}$ Besides oxygen-based functional groups, additional bands are also observed in the range from 500 to $900 \mathrm{~cm}^{-1}$, which are assigned to $\mathrm{C}-\mathrm{Cl}$ stretching modes. ${ }^{77}$ It is likely that reactive chlorine radicals produced via chlorine decomposition under photo-irradiation can bond with nucleophilic C60 via a free radical addition reaction. Such a reaction has also been demonstrated to be the primary mechanism during the photo-chlorination of graphene. $^{78}$

\subsubsection{FT-IR spectroscopy of other carbon-based materials}

As anticipated in section 4.1.5, graphitic carbon nitride $\left(\mathrm{g}-\mathrm{C}_{3} \mathrm{~N}_{4}\right)$ can be synthetized by condensation of low-cost melamine at different temperatures (from $400{ }^{\circ} \mathrm{C}$ up to $700{ }^{\circ} \mathrm{C}$ ) ${ }^{79,80,81,22} \mathrm{IR}$ spectroscopy provides a fast technique to obtain information on the chemical structures obtained at different temperatures. ${ }^{19}$ The FT-IR spectra of $\mathrm{g}-\mathrm{C}_{3} \mathrm{~N}_{4}$ display the typical $\mathrm{C}-\mathrm{N}$ and $\mathrm{C}=\mathrm{N}$ stretching vibrations of $\mathrm{N}$-containing heterocycles in the $1640-1240 \mathrm{~cm}^{-1}$ range. A typical sequence of FT-IR spectra collected at increasing temperature is shown in Figure 10a. The spectrum related to the material synthesised at $400{ }^{\circ} \mathrm{C}$ shows two intense bands at 1608 and $1471 \mathrm{~cm}^{-1}$ and two bands at 1307 and $1100 \mathrm{~cm}^{-1}$ with lower intensity due to melem. ${ }^{22}$ At $500^{\circ} \mathrm{C}$, new bands at 1331 and $1255 \mathrm{~cm}^{-1}$, assigned to melon and $\mathrm{g}_{-} \mathrm{C}_{3} \mathrm{~N}_{4}{ }^{22,82}$ Melon and g$\mathrm{C}_{3} \mathrm{~N}_{4}$ are also characterized by bands at 1635, 1458,1410,1540, 1570, 1320 and $1242 \mathrm{~cm}^{-1}$, observed in the spectra related to the samples prepared at higher temperature. The band centred at $806 \mathrm{~cm}^{-1}$ is related to the out-of-plane bending of triazine rings and is observed in all the spectra without particular modification despite the increase of temperature. ${ }^{83}$ At higher frequencies, above $3000 \mathrm{~cm}^{-1}$, the N-H stretching vibrations of primary and secondary amines are detected. ${ }^{20}$ In particular, bands at $3487 \mathrm{~cm}^{-1}, 3427$ and $3315 \mathrm{~cm}^{-1}$, due to the asymmetric and symmetric $-\mathrm{NH}_{2}$ stretching, and $3150 \mathrm{~cm}^{-1}$, attributed to the $-\mathrm{NH}$ stretching mode, are observed for the materials obtained at 400 and $500{ }^{\circ} \mathrm{C}$. Secondary amines are still present at $700{ }^{\circ} \mathrm{C}$ as revealed by the bands at 3252, 3160 and $3091 \mathrm{~cm}^{-1}$. These features indicate that the melem present at 400 ${ }^{\circ} \mathrm{C}$ condenses forming melon at $500{ }^{\circ} \mathrm{C}$, which further produces $\mathrm{g}-\mathrm{C}_{3} \mathrm{~N}_{4}$ rigid planes. In the rigid planes the dipole moments decrease and therefore the intensity of the absorption bands diminishes. Moreover, the bands observed in the $1640-1240 \mathrm{~cm}^{-1}$ interval increase in intensity up to $700{ }^{\circ} \mathrm{C}$, indicating the fragmentation of the $\mathrm{g}-\mathrm{C}_{3} \mathrm{~N}_{4}$ planes into nanosheets. ${ }^{19}$ 

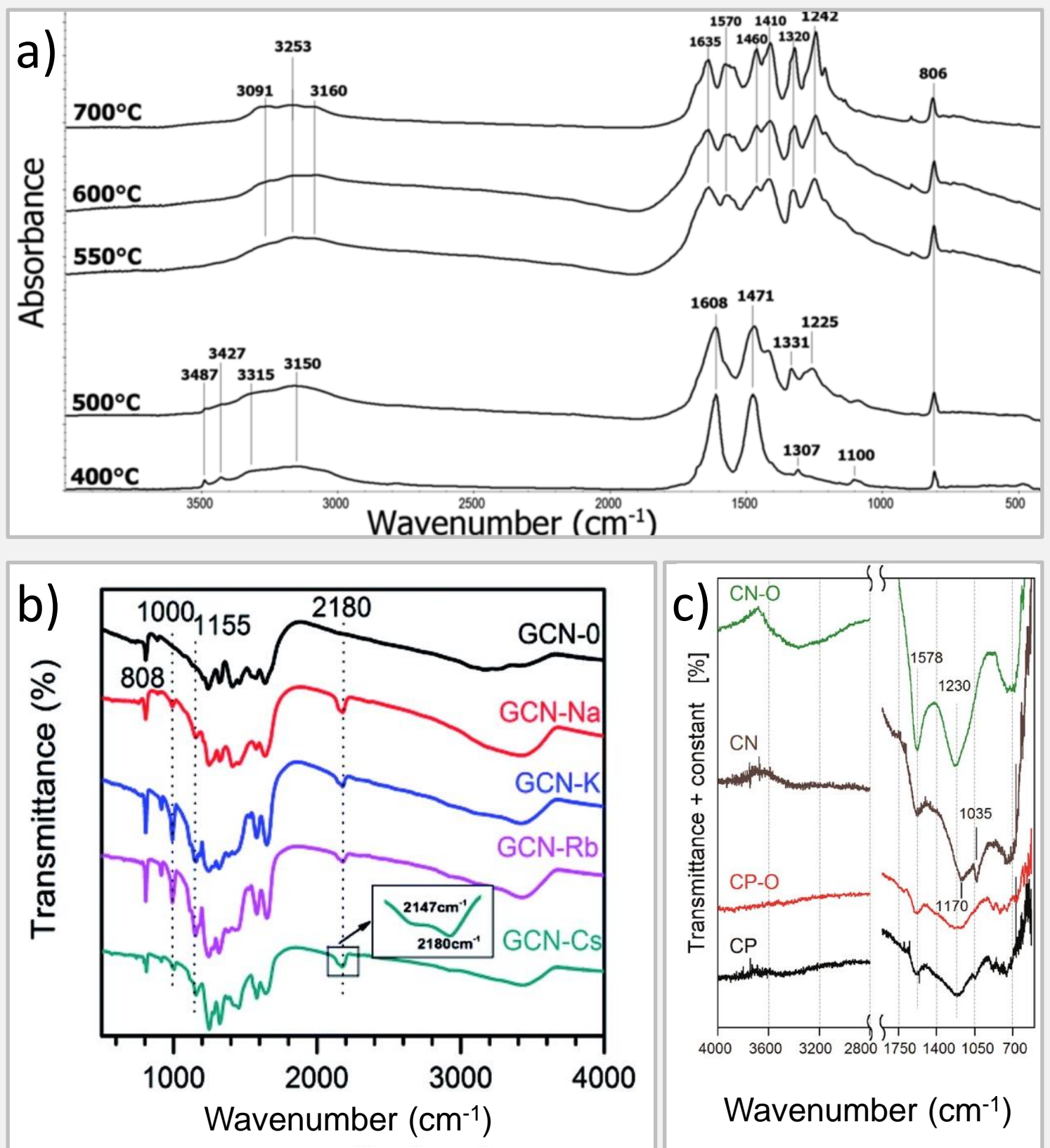

Figure 10. a) FT-IR spectra of melamine $\mathrm{g}-\mathrm{C}_{3} \mathrm{~N}_{4}$ obtained at different temperatures. Reprinted from Mater. Chem. Phys., 193, P. Praus, L. Svoboda, M. Ritz, I. Troppová, M. Šihor, K. Kočí, Graphitic carbon nitride: Synthesis, characterization and photocatalytic decomposition of nitrous oxide, 438-446, Copyright (2017) with permission from Elsevier. b) $\mathrm{g}-\mathrm{C}_{3} \mathrm{~N}_{4}$ via $\mathrm{MCl}(\mathrm{M}=\mathrm{Na}, \mathrm{K}, \mathrm{Rb}, \mathrm{Cs})$ modification. Results of pristine g$\mathrm{C}_{3} \mathrm{~N}_{4}$ are plotted together for comparison. Reproduced from Ref. ${ }^{94}$ with permission from The Royal Society of Chemistry. c) FT-IR spectra of the studied materials. Reprinted from Carbon, 107, M. Seredych, T. J. Bandosz, Nitrogen enrichment of S-doped nanoporous carbon by $\mathrm{g}-\mathrm{C}_{3} \mathrm{~N}_{4}$ : Insight into photosensitivity enhancement, 895-906, Copyright (2016) with permission from Elsevier. 
FT-IR spectroscopy can be employed to investigate the effect of the addition of different atoms or pretreatments on the final structure of $\mathrm{g}-\mathrm{C}_{3} \mathrm{~N}_{4}$. Indeed, the photocatalytic activity of $\mathrm{g}-\mathrm{C}_{3} \mathrm{~N}_{4}$ can be effectively enhanced for example by adding chlorine ${ }^{84,85,86}$ phosphorus, ${ }^{87}$ sulfur, ${ }^{88}$ alkali metal halides, ${ }^{89-93}$ or by hydrochloric acid treatment. ${ }^{83}$ In this frame, due to its high sensitivity to the local structure, FT-IR spectroscopy can be employed to study the framework of melon strands of $\mathrm{g}-\mathrm{C}_{3} \mathrm{~N}_{4}$ by monitoring in-plane long-range periodic ordering. ${ }^{94}$ Figure $10 \mathrm{~b}$ shows the FT-IR spectra of several graphitic carbon nitride (GCN) samples doped with different alkali halides. All the spectra display the typical bands at $808 \mathrm{~cm}^{-1}$ and in the 1200-1900 $\mathrm{cm}^{-1}$ spectroscopic range, which are ascribed to the breathing mode of triazine units and to the stretching vibration modes of aromatic $\mathrm{CN}$ heterocycles, ${ }^{95,21}$ indicating that the effect of alkali halides is to interrupt the intra-layer long-range periodic arrangement without modifying the basic atomic building blocks. Moreover, new components at 1000, 1155, 2147 and $2180 \mathrm{~cm}^{-1}$ are observed for GCN-Na, GCN-K, GCN-Rb and GCN-Cs, which can be assigned to -OH groups located at the surface of g$\mathrm{C}_{3} \mathrm{~N}_{4}{ }^{92,96,97}$ These features are due to the presence of alkali ions preventing the formation of hydrogen bonds. The hydroxyls could be bonded to the amino groups of $\mathrm{g}-\mathrm{C}_{3} \mathrm{~N}_{4} \cdot{ }^{98}$ The broad absorption bands in the $3000-3600 \mathrm{~cm}^{-1}$ region are due to the terminal amino groups. ${ }^{99}$ No vibration related to alkali-related groups is detected, indicating that the melon strands structure of carbon nitride is not modified upon the salt treatment.

To further distinguish the changes in the surface chemistry of the pristine mixture of $g-\mathrm{C}_{3} \mathrm{~N}_{4}$ and a sulfur containing polymer and the final S-doped nanoporous carbon/g- $\mathrm{C}_{3} \mathrm{~N}_{4}$ composite, FT-IR spectra can be collected and the results are shown in Figure 11c. The bands at 1578 and $1230 \mathrm{~cm}^{-1}$ assigned to the aromatic ring stretching mode vibrations of $\mathrm{C}=\mathrm{C}$, related to the carbons, and of $\mathrm{C}=\mathrm{N}$ (for the $\mathrm{CN}$ and $\mathrm{CN}$ O) conjugated with carbonyl/carboxylate groups and nitroso $(\mathrm{N}-\mathrm{O})$ configurations ${ }^{100}$ indicate the occurrence of $\mathrm{CN}$ oxidation. In addition, the band at $1230 \mathrm{~cm}^{-1}$ can be also attributed to aromatic C-N, C-O and might be related to the S-O stretching vibrations. ${ }^{100,101}$ The two bands are increased in intensity after air oxidation, due to the formation of carbonyl/carboxylate groups or N-O configurations. ${ }^{100}$ The weak peak at $1035 \mathrm{~cm}^{-1}$, is assigned to the $\mathrm{C}-\mathrm{O}$ stretching mode and can be related either to the presence of phenol, ether and ester groups in the carbon structure. The band at $1170 \mathrm{~cm}^{-1}$ is related to the stretching vibration of the $\mathrm{C}-\mathrm{O}$ bond. However, the former band can also be due to $\mathrm{N}-\mathrm{O}$ stretching vibrations ${ }^{100}$ and both absorption bands overlap with those due to nitrogen groups originating from graphitic carbon nitride used for the synthesis of the sample ${ }^{101}$, putting in evidence the complexity of the spectra for a correct analysis. FT-IR spectroscopy can be employed to define the chemical structure of complex systems, such as g$\mathrm{C}_{3} \mathrm{~N}_{4} /$ acidified g- $\mathrm{C}_{3} \mathrm{~N}_{4}$ composites used in photocatalysis. ${ }^{102}$ In this case, the intensity of the bands at 1318 and $1240 \mathrm{~cm}^{-1}$, due to the stretching modes of C-NH-C connected units ${ }^{103-105}$ gradually decreases with the increase of acidified $\mathrm{g}-\mathrm{C}_{3} \mathrm{~N}_{4}$ content. Moreover, with increasing amounts of acidified $\mathrm{g}-\mathrm{C}_{3} \mathrm{~N}_{4}$ in the 
composite, a red shift of the bands at $1640 \mathrm{~cm}^{-1}$, related to C-N stretching, and at $1405 \mathrm{~cm}^{-1}$, due to C-N stretching vibrations of heterocycles, is observed. The breathing mode of tri-s-triazine rings at $795 \mathrm{~cm}^{-1}$ follows the same trend, suggesting an electrostatic interaction among tri-s-triazine units of acidified $g-\mathrm{C}_{3} \mathrm{~N}_{4}$ and those of $\mathrm{g}-\mathrm{C}_{3} \mathrm{~N}_{4}$.

The FT-IR spectra of a ternary metal-free hetero-structure made by sheet-on-sheet graphene/ $\mathrm{C}_{3} \mathrm{~N}_{4} /$ carbon dots for the pollutant abatement under visible-light photo-catalysis maintain the bands at 1241, 1323, 1411, 1573 , and $1644 \mathrm{~cm}^{-1}$ ascribed to the $\mathrm{C}-\mathrm{N}$ stretching of heterocycles ${ }^{106}$ and at $806 \mathrm{~cm}^{-1}$ assigned to the breathing mode of triazine units. ${ }^{83}$ This result demonstrates that the solvent-assisted exfoliation and the subsequent loading of carbon dots do not destroy the lattice structure of $\mathrm{C}_{3} \mathrm{~N}_{4}$.

g- $\mathrm{C}_{3} \mathrm{~N}_{4}$ can be modified with graphene oxide and reduced graphene oxide nanosheets with different lateral sizes to obtain a hybrid composed of RGO nanoparticles with size in the 4-135 nm range with enhanced photoactivity with respect to similar size RGO- and GO-containing systems. ${ }^{107}$ The influence of GO and RGO lateral sizes can be investigated by FT-IR spectroscopy, which reveals the depletion of the bands of the oxygen-functional groups for the nanocomposites, indicating that GO underwent to reduction. At the same time, it is possible to observe the appearance of new peaks corresponding to the chemical bonding between $\mathrm{C}$ and $\mathrm{N}$ of $\mathrm{g}-\mathrm{C}_{3} \mathrm{~N}_{4}$ carbon nitride: band at $807 \mathrm{~cm}^{-1}$ due to the breathing mode of triazine units as well as bands at $1245,1320,1420$ and $1560 \mathrm{~cm}^{-1}$ related to $\mathrm{C}-\mathrm{N}$ stretching, peak at $1640 \mathrm{~cm}^{-1}$ of the $\mathrm{C}=\mathrm{N}$ stretching mode and finally a broad band at $3160 \mathrm{~cm}^{-1}$ assigned to the stretching modes of secondary and primary amines. ${ }^{108,109}$

Finally, $\mathrm{B}_{4} \mathrm{C}$ merits to be mentioned. Despite it does not find application in catalysis, it is an advanced material with excellent properties, such as low density, high hardness and high corrosion resistance. Moreover, due to the huge thermal neutron-absorbing cross section $\mathrm{B}_{4} \mathrm{C}$ is capable of capturing thermal neutrons and it finds application in the nuclear shielding field. ${ }^{110}$ The FT-IR spectrum of $\mathrm{B}_{4} \mathrm{C}$ shows the bands related to the $\mathrm{C}-\mathrm{C}$ stretching at $1150-1450 \mathrm{~cm}^{-1}$, the $\mathrm{B}-\mathrm{C}$ stretching at about $1200 \mathrm{~cm}^{-1}$ and the B-O at $1450 \mathrm{~cm}^{-1}$, respectively. ${ }^{110}$

\subsection{Neutrons properties, and Inelastic Neutron Scattering applied to carbons}

Inelastic neutron scattering (INS) technique probes the motion of atoms and molecules within a material. The technique relies on the use of neutrons, which are uncharged particles having a mass very similar to that of a hydrogen atom and a negligible electric dipole moment. For this reason, neutrons interact only with the nucleus of atoms - which is typically only $\sim 0.1 \%$ of the diameter of the atom and $10^{6}$ times smaller than the distance between two atoms - and can penetrate the matter for large distances before being scattered or absorbed. ${ }^{111-113}$ This means that the INS spectra are representative of the entire sample, although large amount of samples (grams) are necessary for the measurements. 
Opposite to Raman and FT-IR spectroscopy, INS has no symmetry selection rules, that means that all the vibrational modes are allowed. ${ }^{111-114}$ The intensity of a band at the characteristic vibrational frequency of a certain chemical species is proportional to: 1) the amount of the species under the neutron beam; 2) the incoherent cross section of the involved species (which is element- and isotope-dependent); and 3) the amplitude of motion of the atoms in the vibrational mode (i.e. how much they displace with respect to equilibrium position), which is larger for light atoms. For most of the elements both the incoherent cross section and the amplitude of motion are very small, except for hydrogen ${ }^{1} \mathrm{H}$, which has an incoherent scattering cross section more than one order of magnitude larger than that of all the other elements, and the smallest mass of any element. This is the reason why INS is extremely powerful in detecting vibrations involving the hydrogenous species, and explains also why an INS spectrum is usually accessible in the whole $0-4000 \mathrm{~cm}^{-1}$ range without exhibiting the cut-off due to the lattice absorption, typically observed in the FT-IR spectra of most of the materials. ${ }^{111-113}$

In carbon-based materials hydrogen atoms are present mainly at the edges of the $\mathrm{sp}^{2}$ graphitic domains constituting the basic structural units, and in less extent in functional groups containing other heteroatoms (such as carboxylic groups, - $\mathrm{COOH}$, or hydroxyl groups, $-\mathrm{OH}$ ). The type and relative amount of these species influence the surface properties of all the carbon-based materials, are responsible for the catalytic activity of metal-free carbons as well as for the adsorption of organic reactants during the catalysis, and influence also the deposition of metal nanoparticles during the preparation of carbon-supported catalysts. ${ }^{115-117}$ Albeit not diffuse as IR and Raman spectroscopies, INS has been widely applied to the investigation of carbon-based materials ${ }^{118-127}$ and carbon-supported catalysts, ${ }^{128-135}$ offering unprecedented details on the surface properties at the atomic level. Most of the works are related to activated carbons or coal, ${ }^{118-122,135-137}$ while there are very few reports on INS applied to other carbonaceous materials such as graphite, graphene and carbon nanotubes, the latter motivated mainly by their potential in $\mathrm{H}_{2}$ absorption. ${ }^{123-125,127}$ The most prolific research groups in this field are those of Albers and Parker, ${ }^{111,113,118,122,129-131,133,136}$ who published the first INS spectra of activated carbons in the late 1990s. Although the performances of the neutron facilities have been largely improved in the last decade with the consequent progress in the overall quality of the INS spectra, these are still the reference papers in the field of INS spectroscopy applied to carbonaceous materials.

\subsubsection{INS spectra of activated carbons}

A typical INS spectrum of an activated carbon is shown in Figure 11a. The absorption band centred around $3060 \mathrm{~cm}^{-1}, 1200 \mathrm{~cm}^{-1}$ and in the $800-1000 \mathrm{~cm}^{-1}$ region are assigned respectively to the stretching, in-plane and out-of-plane bending modes of the hydrogen species belonging to the condensed rings edges. ${ }^{26,28}$ The weak bands in the $700-400 \mathrm{~cm}^{-1}$ region are assigned to the so called riding vibrations, which are 
substantial movements of the hydrogen atoms indirectly induced by $\mathrm{C}$-C torsion modes of the carbon atoms at the edges of the graphitic fragments. In other words, the $\mathrm{H}$ atoms move in phase with the vibrations of the surface $\mathrm{C}$ atoms, as a rider moves with their horse. ${ }^{28,138}$

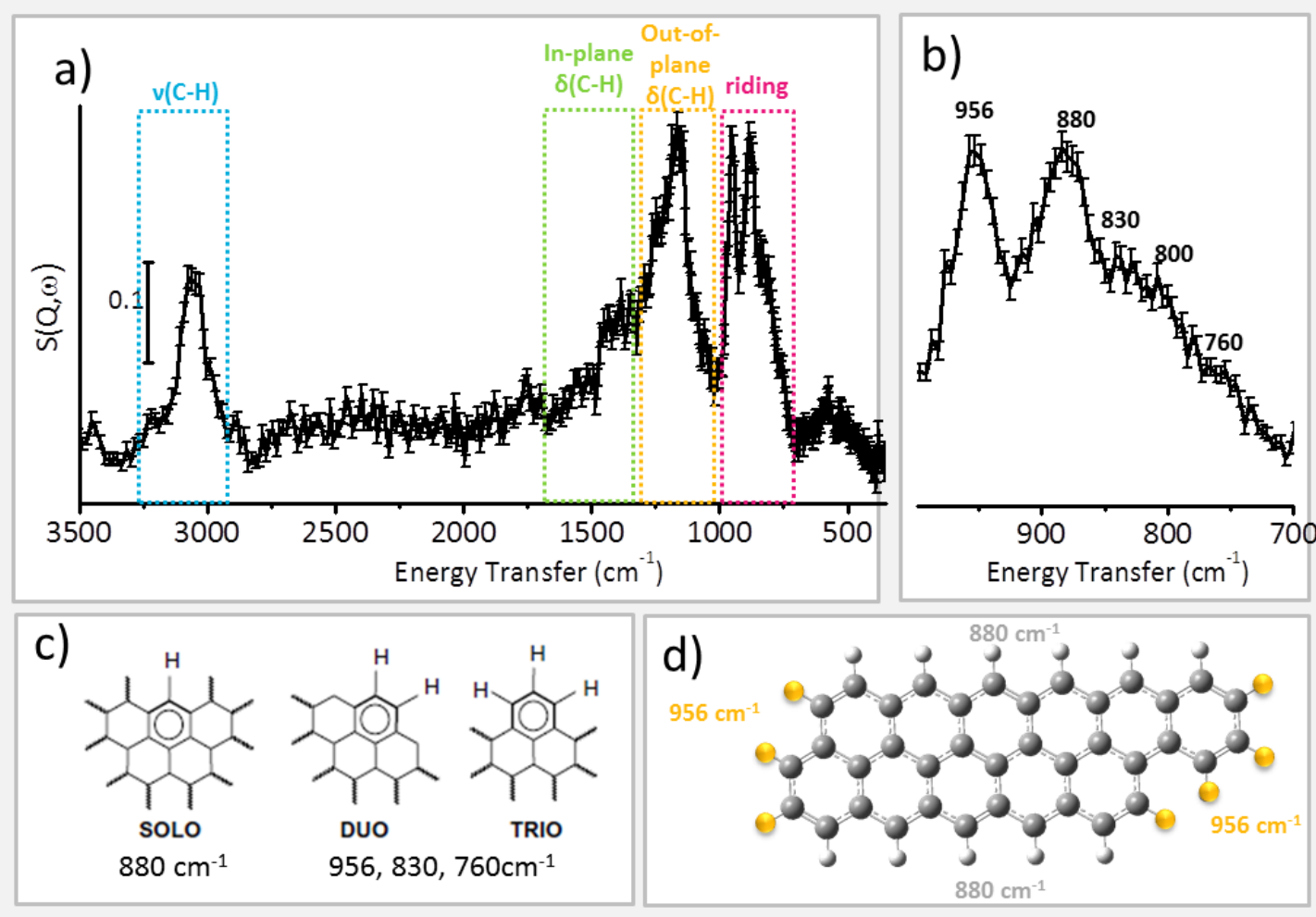

Figure 11. Part a) INS spectrum of an activated carbon of wood origin and assignment of the main absorption bands. Part b) Magnification of the $1000-700 \mathrm{~cm}^{-1}$ region, containing the characteristic out-ofplane $\delta(\mathrm{C}-\mathrm{H})$ vibrational modes. Reproduced from Ref. ${ }^{28}$ with permission from The Royal Society of Chemistry. Part c) Description of solo, duo, and trio structures and corresponding vibrational modes. Reprinted from Carbon, 43, A. Centrone, L. Brambilla, T. Renouard, L. Gherghel, C. Mathis, K. Mullen, G. Zerbi, Structure of new carbonaceous materials: The role of vibrational spectroscopy, 1593-1609, Copyright (2005) with permission from Elsevier.

Part d) Schematic representation of the out-of-plane $\delta(\mathrm{C}-\mathrm{H})$ vibrational modes for regular and irregular borders. Carbon atoms are shown in grey, hydrogen belonging to regular borders in white, and hydrogen belonging to irregular borders in yellow. The contribution at $880 \mathrm{~cm}^{-1}$ is connected to an in-phase oscillation of solo species on well-extended borders, while the intense mode at $958 \mathrm{~cm}^{-1}$ is connected to out-of-phase modes at duo and trio sites that characterize a defective and not extended border. Reprinted from A. Piovano, A. Lazzarini, R. Pellegrini, G. Leofanti, G. Agostini, S. Rudić, A. L. Bugaev, C. Lamberti and E. Groppo, Adv. Condens. Matter Phys., 2015, 2015, Article ID 803267, 8 pages. Acknowledgements for reproduction of Hindawi material in RSC publications. 
It has been demonstrated that the relative intensity of the above mentioned bands depends on the origin of the activated carbon (e.g. wood, peat or coconut), ${ }^{118}$ on the activation procedure, ${ }^{28}$ and on the eventual post-treatment. The most characteristic region is that of the out-of-plane C-H bending modes (Figure 11b), where well-defined bands are observed at 956, 880, 830, 800 and $760 \mathrm{~cm}^{-1}$. Most of these bands are also observed in the DRIFT spectra of the same carbons (Figure 7), and can be assigned to specific structures at the "borders" of the $\mathrm{sp}^{2}$ domains, which are defined as solo, duo and trio referring to the number of adjacent aromatic $\mathrm{C}-\mathrm{H}$ groups which vibrate out-of-plane in the fused rings (Figure 11c). In particular, according to literature ${ }^{26,28,118}$ and to recent calculations, ${ }^{139}$ the band at $880 \mathrm{~cm}^{-1}$ is associated to solo species belonging to regular borders at extended $\mathrm{sp}^{2}$ domains, which vibrate in phase (Figure 11d). The band at 956 $\mathrm{cm}^{-1}$, which is usually absent in the DRIFT spectra, was assigned only recently ${ }^{28,139}$ to $d u o$ and trio species belonging to irregular borders of the $\mathrm{sp}^{2}$ domains, which vibrate not in phase (Figure 11d). Hence, the relative intensity of the two bands at 880 and $956 \mathrm{~cm}^{-1}$ indicates the degree of regularity of the $\mathrm{sp}^{2}$ domains. It is worth noticing here that a full assignment of the bands observed by INS is possible only by employing quantum chemistry methods to calculate vibrational frequencies of a suitable model. While for IR spectroscopy the quantitative evaluation of the band intensities is not an easy task (because they depend on the vibration polarization), for INS a quantitative analysis is usually easy and robust, ${ }^{114}$ since the intensity of an INS spectrum depends on the nucleus incoherent cross section and to the square of the normal mode displacements. The limiting step in the accuracy of calculation for carbonaceous material is the choice of the model, which should be big enough to be representative of the system, but sufficiently small to be computable in a reasonable time scale.

The potential of INS spectroscopy in the analysis of activated carbons is illustrated in Figure 12, which reports a few INS spectra of activated carbons differing in the origin of the natural raw material ${ }^{118}$ (part a), in the activation procedure ${ }^{28}$ (part b), or in the post-activation treatment ${ }^{27}$ (part c). Figure 12a compares the INS spectra of three activated carbons derived from different natural sources (namely, beech, coconut shell and peat). ${ }^{118}$ The three spectra show a different absolute intensity (that scales with the amount of hydrogen) and distinct differences in the out-of-plane $\mathrm{C}-\mathrm{H}$ bending region and in particular in the relative intensity of the band at $880 \mathrm{~cm}^{-1}$, suggesting that the raw material affects the extension and regularity of the graphitic domains in the corresponding activated carbon. It is worth to notice that discrepancies between the intensity of the INS spectra and the hydrogen content in carbon materials have been also reported. In particular, Fillaux et al. ${ }^{140}$ suggested that a part of the hydrogen species in graphitic carbons behave like free protons and therefore they respond in a different way.

Figure $12 \mathrm{~b}$ shows the INS spectra of two carbons having the same origin (wood) but a different activation treatment (in steam or in the presence of phosphoric acid). 

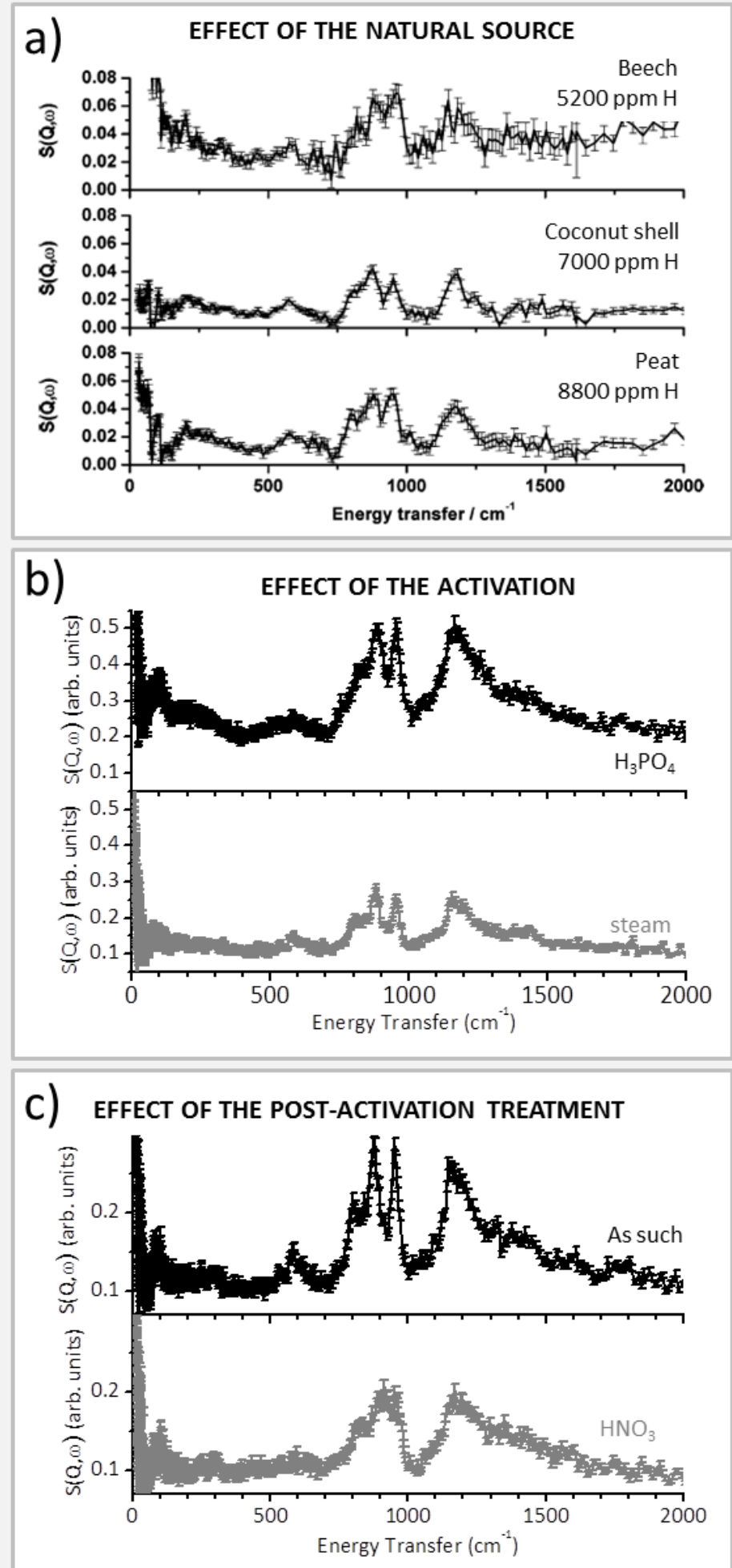

Figure 12. INS spectra of activated carbons differing in the origin of the natural raw material (part a, reproduced from Ref. ${ }^{118}$ with permission from The Royal Society of Chemistry), in the activation procedure (part b, reproduced from Ref. ${ }^{28}$ with permission from PCCP Owner Societies) or in the postactivation treatment (part c, reproduced from Ref. ${ }^{27}$ with permission from The Royal Society of Chemistry). 
They differ again in the absolute intensity - the chemically activated carbon contains more hydrogen - and in the relative abundance of the hydrogen termination - the chemically activated carbon presents less extended and more irregular borders. ${ }^{28}$

Figure 12c shows the INS spectra of a chemically activated carbon of wood origin and of the same carbon subjected to a post-activation treatment in $\mathrm{HNO}_{3},{ }^{27}$ which is known to introduce oxidized functional groups. ${ }^{43,44,141-143}$ The latter has a lower intensity, which indicates that a fraction of the hydrogen terminations has been consumed in favour of new oxygenated functional groups. In addition, the absorption bands at 956,830 and $760 \mathrm{~cm}^{-1}$ significantly decrease in intensity, while that at $880 \mathrm{~cm}^{-1}$ upward shift to $912 \mathrm{~cm}^{-1}$. These results indicate that the treatment in $\mathrm{HNO}_{3}$ affects mainly the irregular borders of the graphitic layers, which are likely attacked by oxygenated functional groups. The presence of these electronwithdrawing species at the irregular borders has indirect consequences also on the regular extended edges, as reflected by the substantial shift of the band associated to the vibrations of the corresponding $\mathrm{C}-\mathrm{H}$ terminations.

\subsubsection{INS spectroscopy of other carbonaceous materials}

Also other carbon-based materials (diamond, various forms of graphite, fullerenes, nanotubes and so on) have been extensively studied by INS spectroscopy, when readily available. The INS spectra of highly oriented pyrolytic graphite and C70 fullerene ${ }^{144,145}$ are shown in Figure 13a, as examples of carbon-based materials having formally no hydrogen termination and characterized by a completely different vibrational behaviour. The vibrational bands in the spectrum of graphite (spectrum a1 in Figure 13a) are very broad and separated into four main groups, which can be approximately described as: ${ }^{114,124,146}$ local in-plane stretches at $1400-1600 \mathrm{~cm}^{-1}$, local in-plane bends at $600-900 \mathrm{~cm}^{-1}$, sheet deformations at $400-500 \mathrm{~cm}^{-1}$ and the rigid sheet modes below $100 \mathrm{~cm}^{-1}$ (the latter not shown in Figure 13). Opposite to graphite, the INS spectrum of the C70 fullerene (spectrum a2 in Figure 13a) has a molecular-like character, and contains a multitude of narrow vibrational bands having similar intensities. Such a rich spectrum is in contrast to both Raman and IR spectra, that contain a limited number of vibrational bands with substantially different intensities. This is a consequence of the fact that all the modes are allowed in INS spectroscopy, and that all the atoms in the mode have the same scattering cross section and consequently similar amplitudes of vibration. All the bands have been recently re-assigned based on periodic density functional theory calculations. ${ }^{144}$

The INS spectrum of graphite progressively broadens upon reducing the size of the $\mathrm{sp}^{2}$ domains (e.g by ball-milling). For example, the INS spectrum of graphene (obtained by thermal exfoliation of graphite oxide) does not contain any distinguishable feature, but only an increasing background in the low frequency part (not shown). Things drastically change upon hydrogenation. 


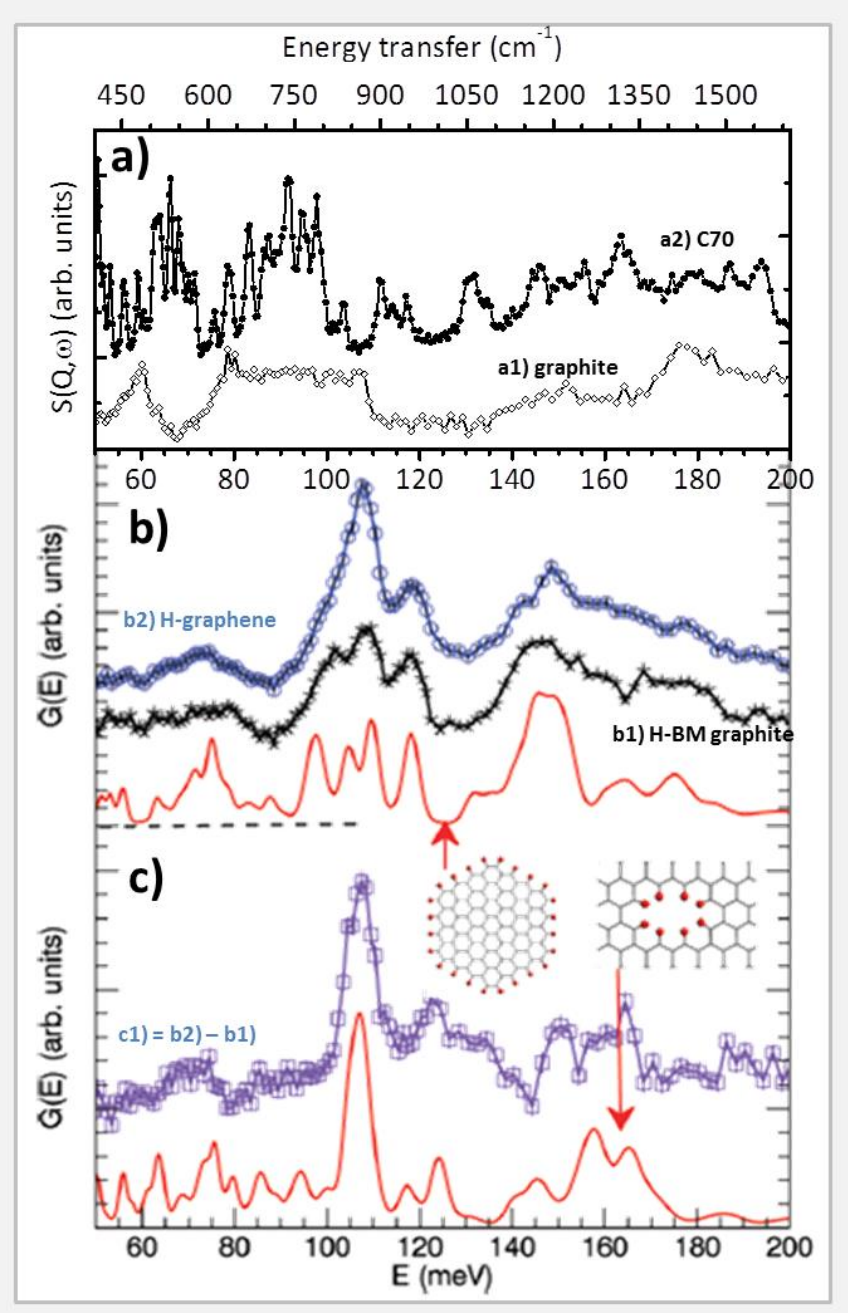

Figure 13. Part a) INS spectra of highly oriented pyrolytic graphite (spectrum a1, reprinted from J. K. Walters, R. J. Newport, S. F. Parker and W. S. J. Phys. Condens. Matter, 1995, 7, 10059-10073. Acknowledgements for reproduction of IOP Publishing material in RSC publications) and C70 fullerene (spectrum a2, reprinted from K. Refson and S. F. Parker, Chem. Open, 2015, 4, 620-625. Acknowledgements for reproduction of Wiley-VCH Verlag $\mathrm{GmbH} \&$ Co. KGaA material in RSC publications) as examples of carbon-based materials having formally no hydrogen termination. Part b) Experimental INS spectra of hydrogenated nano-graphite (obtained by mechanical ball-milling of graphite, spectrum b1) and hydrogenated graphene (spectrum b2), the latter satisfactorily reproduced by a large PAH molecule (inset and red line in part b), with all the edges terminated with hydrogen. Part c) Difference between the spectra b2 and b1 (spectrum c1) and simulated spectrum for $\mathrm{H}$ chemisorbed inside small voids (inset and full line in $\mathrm{c}$ ). Parts $\mathrm{b}$ and $\mathrm{c}$ have been reproduced from Ref. ${ }^{146}$ with permission from PCCP Owner Societies.

Figure 13b compares the experimental INS spectra of hydrogenated nano-graphite (obtained by mechanical ball-milling of graphite) and hydrogenated graphene. ${ }^{124,146}$ The INS spectrum of H-nanographite (spectrum 
b1 in Figure 13b) is quite similar to those of activated carbons (Figure 11), especially concerning the position in frequency of the bands, which can be attributed to common dynamical features. The spectrum is satisfactorily reproduced by a large PAH molecule (inset and full line in Figure 13b), with all the edges terminated with hydrogen. This means that the ball-milling and successive hydrogenation procedures cause a disruption of the regular graphitic domains and that single hydrogen saturation per edge carbon atoms applies. This demonstrates the effectiveness of defects in dissociating the molecule of hydrogen and trapping atomic hydrogen in covalent bonds, a phenomenon of potential interest in catalysis.

By contrast, the spectrum of $\mathrm{H}$-graphene (spectrum b2 in Figure 13b) is different, and dominated by a peak at $108 \mathrm{meV}\left(870 \mathrm{~cm}^{-1}\right)$, with a broad tail around $118 \mathrm{meV}\left(950 \mathrm{~cm}^{-1}\right)$. This band has been indicated as the spectroscopic fingerprint for $\mathrm{H}$ atoms chemisorbed at sites specific for $\mathrm{H}$-graphene sample, as clearly indicated by subtracting the spectrum of $\mathrm{H}$-nanographite to that of H-graphene (spectrum $\mathrm{c} 1$ in Figure 13c). This extra dynamical features in $\mathrm{H}$-graphene has been attributed to $\mathrm{H}$ covalently bonded to in-plane defects (e.g. small voids), which are produced during the synthesis process. Indeed, the experimental INS spectrum of the $\mathrm{H}$-graphene has been reproduced satisfactorily by accounting for a proportion of $\mathrm{H}$ chemisorbed in equal proportions, at the edges and inside small voids (inset and full line in Figure 13c).

\subsection{Conclusions (and future perspectives)}

Vibrational spectroscopies are among the most powerful techniques applied to the characterisation of metal-free carbon materials. However, carbon-based materials usually show very complex spectra that can generate a lot of problems as for the interpretation, especially when considering new composite/hybrid Ccontaining systems.

In the present Chapter, different types of materials have been examined in order to correlate the spectroscopic features with the modification produced by treating the materials with opportune molecules or upon addition of dopants. The goal was to unravel the changes occurring on the materials during the synthesis and to establish structure-activity relationships. Efforts have been made to provide different case studies by which it is possible to have a panorama on the kind of information provided by Raman, IR and INS spectroscopies. It is shown that these techniques give complementary insights at atomic scale on the examined samples.

In the next future, to improve atom and energy efficiency for industrial applications, catalyst design will further gain strategic importance. In this frame, intense efforts are dedicated to the possibility to obtain green metal-free materials required in the area of scaling up carbonaceous catalysts. Therefore, the results here presented highlight the pivotal significance of spectroscopic characterisation of metal-free carbonaceous nanomaterials. Indeed, the deep understanding of the structure at a nanometric level, which can be gained by performing an extended characterisation, will help in unravelling the nature of the active 
sites leading to the design and synthesis of more performant and stable catalysts. 


\section{References}

1 A. C. Ferrari and J. Robertson, Phys. Rev. B, 2000, 61, 14095-14107.

2 R. P. Vidano, D. B. Fischbach, L. J. Willis and T. M. Loehr, Solid State Commun., 1981, 39, 341344.

3 R. J. Nemanich and S. A. Solin, Phys. Rev. B, 1979, 20, 392-401.

4 I. Pócsik, M. Hundhausen, M. Koós and L. Ley, J. Non. Cryst. Solids, 1998, 227-230, 1083-1086.

5 A. Lazzarini, Rend. Lincei, 2017, 28, 29-42.

6 R. Beams, L. Gustavo Cançado and L. Novotny, J. Phys. Condens. Matter, 2015, 27, 83002.

7 A. C. Ferrari and D. M. Basko, Nat. Nanotechnol., 2013, 8, 235-246.

8 C. Zhang, R. Hao, H. Liao and Y. Hou, Nano Energy, 2013, 2, 88-97.

9 D. R. Dreyer, A. D. Todd and C. W. Bielawski, Chem. Soc. Rev., 2014, 43, 5288.

10 S. Eigler, Chem. - A Eur. J., 2016, 22, 7012-7027.

11 I. Jung, D. A. Dikin, R. D. Piner and R. S. Ruoff, Nano Lett., 2008, 8, 4283-4287.

12 D. Mandal, P. Routh and A. K. Nandi, ChemistrySelect, 2017, 2, 3163-3171.

13 L. F. Dumée, C. Feng, L. He, F.-M. Allioux, Z. Yi, W. Gao, C. Banos, J. B. Davies and L. Kong, Appl. Surf. Sci., 2014, 322, 126-135.

14 S. Iijima and T. Ichihashi, Nature, 1993, 363, 603-605.

15 S. Iijima, Nature, 1991, 354, 56-58.

16 R. Graupner, J. Raman Spectrosc., 2007, 38, 673-683.

17 S. Banerjee and S. S. Wong, Nano Lett., 2004, 4, 1445-1450.

18 K. K. Han, C. C. Wang, Y. Y. Li, M. M. Wan, Y. Wang, J. H. Zhu, H. M. Cheng and M. Antonietti, RSC Adv., 2013, 3, 9465.

19 P. Praus, L. Svoboda, M. Ritz, I. Troppová, M. Šihor and K. Kočí, Mater. Chem. Phys., 2017, 193, $438-446$.

20 M. K. Marchewka, Mater. Sci. Eng. B, 2002, 95, 214-221.

21 Q. Xiang, J. Yu and M. Jaroniec, J. Phys. Chem. C, 2011, 115, 7355-7363.

22 I. Papailias, T. Giannakopoulou, N. Todorova, D. Demotikali, T. Vaimakis and C. Trapalis, Appl. Surf. Sci., 2015, 358, 278-286.

23 K.-D. Henning and H. von Kienle, in Ullmann's Encyclopedia of Industrial Chemistry, Wiley-VCH, 2010.

24 R. Schlogl, in Handbook of heterogeneous catalysis, eds. G. Ert, H. Knozinger, F. Schuth and J. Weitkamp, Wiley-VCH, 2008, p. 357.

H. Marsh and F. Rodriguez-Reinoso, in Activated carbon, Elsevier B.V, 2006, p. 13. 
A. Centrone, L. Brambilla, T. Renouard, L. Gherghel, C. Mathis, K. Mullen and G. Zerbi, Carbon N. Y., 2005, 43, 1593-1609.

A. Lazzarini, R. Pellegrini, A. Piovano, S. Rudić, C. Castan-Guerrero, P. Torelli, M. R. Chierotti, R. Gobetto, C. Lamberti and E. Groppo, Catal. Sci. Technol., 2017,7, 4162-4172.

A. Lazzarini, A. Piovano, R. Pellegrini, G. Leofanti, G. Agostini, S. Rudić, M. R. Chierotti, R. Gobetto, A. Battiato, G. Spoto, A. Zecchina, C. Lamberti and E. Groppo, Catal. Sci. Technol., 2016, 6, 4910-4922.

R. A. Friedel and G. L. Carlson, J. Phys. Chem., 1971, 75, 1149-1151.

V. Ţucureanu, A. Matei and A. M. Avram, Crit. Rev. Anal. Chem., 2016, 46, 502-520.

C. Moreno-Castilla, M. . López-Ramón, F. Carrasco-Marín, M. V Lopez-Ramon and F. CarrascoMarin, Carbon N. Y., 2000, 38, 1995-2001.

$\dagger$ E. Fuente, † J. A. Menéndez, † M. A. Díez, † and D. Suárez and † M. A. Montes-Morán*, , DOI:10.1021/JP027482G.

33 F. Rositani, P. L. Antonucci, M. Minutoli, N. Giordano and A. Villari, Carbon N. Y., 1987, 25, 325332.

A. O. Odeh, J. Fuel Chem. Technol., 2015, 43, 129-137.

J. Lee, K. H. Kim and E. E. Kwon, Renew. Sustain. Energy Rev., 2017, 77, 70-79.

T. Zerlia, Fuel, 1985, 64, 1310-1312.

C. Yang, Fuel, 1995, 74, 543-548.

P. K. Chu and L. Li, Mater. Chem. Phys., 2006, 96, 253-277.

A. C. Ferrari, S. E. Rodil and J. Robertson, Phys. Rev. B, 2003, 67, 155306.

M. T. Timko, J. A. Wang, J. Burgess, P. Kracke, L. Gonzalez, C. Jaye and D. A. Fischer, Fuel, 2016, 163, 223-231.

T. Kar, S. Scheiner, U. Adhikari and A. K. Roy, J. Phys. Chem. C, 2013, 117, 18206-18215.

U. Adhikari, S. Scheiner, A. K. Roy and T. Kar, Carbon N. Y., 2014, 73, 194-205.

J. Collins, T. Ngo, D. Qu and M. Foster, Carbon N. Y., 2013, 57, 174-183.

J. Collins, D. Zheng, T. Ngo, D. Qu and M. Foster, Carbon N. Y., 2014, 79, 500-517.

F. Cesano, M. M. Rahman, S. Bertarione, J. G. Vitillo, D. Scarano and A. Zecchina, Carbon N. Y., 2012, 50, 2047-2051.

C. Tang and Q. Zhang, Adv. Mater., , DOI:10.1002/adma.201604103.

X. Liu and L. Dai, Nat. Rev. Mater., 2016, 1, 16064.

N. A. Fathy, M. A. Shouman and R. M. M. Aboelenin, ASIA-PACIFIC J. Chem. Eng., 2016, 11, 836845. 
304.

50 M. Sangermano, S. Marchi, L. Valentini, S. B. Bon and P. Fabbri, Macromol. Mater. Eng., 2011, 296, 401-407.

51 A. C. Obreja, D. Cristea, R. Gavrila, V. Schiopu, A. Dinescu, M. Danila and F. Comanescu, Appl. Surf. Sci., 2013, 276, 458-467.

D. W. Lee, L. De Los Santos V., J. W. Seo, L. L. Felix, A. Bustamante D., J. M. Cole and C. H. W. Barnes, J. Phys. Chem. B, 2010, 114, 5723-5728.

D. W. Chang, E. K. Lee, E. Y. Park, H. Yu, H.-J. Choi, I.-Y. Jeon, G.-J. Sohn, D. Shin, N. Park, J. H. Oh, L. Dai and J.-B. Baek, J. Am. Chem. Soc., 2013, 135, 8981-8988.

S. Cravanzola, F. Cesano, G. Magnacca, A. Zecchina and D. Scarano, RSC Adv., 2016, 6, 5900159008.

S. Indrawirawan, H. Sun, X. Duan and S. Wang, J. Mater. Chem. A, 2015, 3, 3432-3440.

Y. Zhang, Z. Sun, H. Wang, Y. Wang, M. Liang and S. Xue, RSC Adv., 2015, 5, 10430-10439.

B. Shateesh, G. B. Markad and S. K. Haram, Electrochim. Acta, 2016, 200, 53-58.

S. Rana and S. B. Jonnalagadda, Catal. Commun., 2017, 92, 31-34.

S. Yang, X. Feng, X. Wang and K. Müllen, Angew. Chemie Int. Ed., 2011, 50, 5339-5343.

M. J. Ju, J. C. Kim, H.-J. Choi, I. T. Choi, S. G. Kim, K. Lim, J. Ko, J.-J. Lee, I.-Y. Jeon, J.-B. Baek and H. K. Kim, ACS Nano, 2013, 7, 5243-5250.

Y. Xue, J. Liu, H. Chen, R. Wang, D. Li, J. Qu and L. Dai, Angew. Chemie Int. Ed., 2012, 51, 1212412127.

B. B. Wang, M. K. Zhu, K. Ostrikov, R. W. Shao and K. Zheng, J. Mater. Chem. C, 2015, 3, 11061112.

F. Karlický, K. Kumara Ramanatha Datta, M. Otyepka and R. Zbořil, ACS Nano, 2013, 7, 64346464.

J. H. Lehman, M. Terrones, E. Mansfield, K. E. Hurst and V. Meunier, Carbon N. Y., 2011, 49, 25812602.

D. Tasis, N. Tagmatarchis, A. Bianco, M. Prato, D. Tasis, N. Tagmatarchis, A. Bianco and M. Prato, Chem. Rev., 2006, 106, 1105-1136.

G. Cravotto, D. Garella, E. C. Gaudino, F. Turci, S. Bertarione, G. Agostini, F. Cesano and D. Scarano, New J. Chem., , DOI:10.1039/c0nj00892c.

J. Zhang, H. Zou, Q. Qing, Y. Yang, Q. Li, Z. Liu, X. Guo and Z. Du, J. Phys. Chem. B, 2003, 107, 3712-3718.

A. Misra, P. K. Tyagi, M. K. Singh and D. S. Misra, Diam. Relat. Mater., 2006, 15, 385-388. 
Proc., 2008, 1017, 159-163.

L. Moradi and I. Etesami, Fullerenes, Nanotub. Carbon Nanostructures, 2016, 24, 213-218.

C. Preston, D. Song, J. Taillon, J. Cumings and L. Hu, Nanotechnology, 2016, 27, 445601.

M. Prato, J. Mater. Chem., 1997, 7, 1097-1109.

M. R. Resmi, S. Ma, R. Caprioli and T. Pradeep, Chem. Phys. Lett., 2001, 333, 515-521.

J. Wu, W. Li, J. D. Fortner, M. Wiesner, P. Fioux, M. A. Gomez-Fatou, A. M. Benito, W. K. Maser, M. T. Martinez, F. Zerbetto, A. Koch and J. B. Hughes, Environ. Sci. Nano, 2017, 4, 117-126.

J. Lee, M. Cho, J. D. Fortner, J. B. Hughes and J.-H. Kim, Environ. Sci. Technol., 2009, 43, 48784883.

Y. S. Hwang and Q. Li, Environ. Sci. Technol., 2010, 44, 3008-3013.

F. Cataldo, Carbon N. Y., 1994, 32, 437-443.

Y. Gao, X. Wu, X. C. Zeng, E. Wang, D. Geohagan, Z. Y. Zhang, C. Xiao, K. Deng, Z. Liu, S.

Asahina, H. Kazumori, M. O’Keeffe, O. Terasaki, J. F. Stoddart and O. M. Yaghi, J. Mater. Chem. A, 2014, 2, 5910-5914.

S. Yang, Y. Gong, J. Zhang, L. Zhan, L. Ma, Z. Fang, R. Vajtai, X. Wang and P. M. Ajayan, Adv. Mater., 2013, 25, 2452-2456.

Y. Zhang, Q. Pan, G. Chai, M. Liang, G. Dong, Q. Zhang and J. Qiu, Sci. Rep., 2013, 3, 1943.

B. Jürgens, E. Irran, J. Senker, P. Kroll, H. Müller and W. Schnick, J. Am. Chem. Soc., 2003, 125, $10288-10300$.

P. Wu, J. Wang, J. Zhao, L. Guo and F. E. Osterloh, J. Mater. Chem. A, 2014, 2, 20338-20344.

H. Yin, Q. Guo, D. He, J. Li and S. Sun, Chem. Phys. Lett., 2017, 669, 22-28.

Z. Yao, H. Nie, Z. Yang, X. Zhou, Z. Liu and S. Huang, Chem. Commun., 2012, 48, 1027-1029.

C. Liu, Y. Zhang, F. Dong, A. H. Reshak, L. Ye, N. Pinna, C. Zeng, T. Zhang and H. Huang, Appl. Catal. B Environ., 2017, 203, 465-474.

W.-J. Ong, L.-L. Tan, S.-P. Chai and S.-T. Yong, Dalt. Trans., 2015, 44, 1249-1257.

B. Chai, J. Yan, C. Wang, Z. Ren and Y. Zhu, Appl. Surf. Sci., 2017, 391, 376-383.

M. Seredych and T. J. Bandosz, Carbon, 2016, 107, 895-906.

W. Fang, J. Liu, L. Yu, Z. Jiang and W. Shangguan, Appl. Catal. B Environ., 2017, 209, 631-636.

S. Hu, F. Li, Z. Fan, F. Wang, Y. Zhao, Z. Lv, M. Antonietti, J. Z. Gui and X. C. Wang, Dalt. Trans., 2015, 44, 1084-1092.

M. Zhang, X. Bai, D. Liu, J. Wang and Y. Zhu, Appl. Catal. B Environ., 2015, 164, 77-81. 2950.

H. Liu, D. Chen, Z. Wang, H. Jing and R. Zhang, Appl. Catal. B Environ., 2017, 203, 300-313. 
94 Y. Xu, Y. Gong, H. Ren, W. Liu, L. Niu, C. Li, X. Liu, H. Xu, J. Martin-Calleja, T. Zhang and J. Yao, RSC Adv., 2017, 7, 32592-32600.

95 Y. Shang, X. Chen, W. Liu, P. Tan, H. Chen, L. Wu, C. Ma, X. Xiong and J. Pan, Appl. Catal. B Environ., 2017, 204, 78-88.

96 X. L. Wang, W. Q. Fang, H. F. Wang, H. Zhang, H. Zhao, Y. Yao, H. G. Yang and W. Schnick, J. Mater. Chem. A, 2013, 1, 14089.

97 H. Yu, R. Shi, Y. Zhao, T. Bian, Y. Zhao, C. Zhou, G. I. N. Waterhouse, L.-Z. Wu, C.-H. Tung and T. Zhang, Adv. Mater., 2017, 29, 1605148.

98 A. Thomas, A. Fischer, F. Goettmann, M. Antonietti, J.-O. Müller, R. Schlögl and J. M. Carlsson, J. Mater. Chem., 2008, 18, 4893.

99 L. Lin, H. Ou, Y. Zhang and X. Wang, ACS Catal., 2016, 6, 3921-3931.

100 J. Zawadzki and M. Wisniewskí, Carbon N. Y., 2003, 41, 2257-2267.

101 Y. Li, H. Zhang, P. Liu, D. Wang, Y. Li and H. Zhao, Small, 2013, 9, n/a-n/a.

102 X. Yang, F. Qian, G. Zou, M. Li, J. Lu, Y. Li and M. Bao, Appl. Catal. B Environ., 2016, 193, $22-35$.

103 Q. Liang, Z. Li, X. Yu, Z.-H. Huang, F. Kang and Q.-H. Yang, Adv. Mater., 2015, 27, 4634-4639.

104 X. Du, G. Zou, Z. Wang and X. Wang, Nanoscale, 2015, 7, 8701-8706.

105 Y.-P. Zhu, T.-Z. Ren and Z.-Y. Yuan, ACS Appl. Mater. Interfaces, 2015, 7, 16850-16856.

106 F. Zhang, Q. Wen, M. Hong, Z. Zhuang and Y. Yu, Chem. Eng. J., 2017, 307, 593-603.

107 M. Aleksandrzak, W. Kukulka and E. Mijowska, Appl. Surf. Sci., 2017, 398, 56-62.

108 X. Li, J. Zhang, L. Shen, Y. Ma, W. Lei, Q. Cui and G. Zou, Appl. Phys. A, 2009, 94, 387-392.

109 M. Groenewolt and M. Antonietti, Adv. Mater., 2005, 17, 1789-1792.

110 Y. Zhang, Y. Zhang, H. Gong, J. Yu, J. Zhao, Z. Zhang and Y. Zhang, J. Sol-Gel Sci. Technol., 2016, 80, 683-689.

111 S. F. Parker, Johnson Matthey Technol. Rev., 2016, 60, 132-144.

112 R. Pynn, in Neutron Scattering Applications and Techniques, ed. L. Liang, Springer Science+Business Media, LLC 2009, 2009, pp. 1-29.

113 S. F. Parker, D. Lennon and P. W. Albers, Appl. Spectrosc., 2011, 65, 1325-1341.

114 P. C. H. Mitchell, F. S. Parker, A. J. Ramirez-Cuesta and J. Tomkinson, Vibrational Spectroscopy with Neutrons, World Scientific, London, UK, 2005.

115 J. L. Figueiredo and M. F. R. Pereira, Catal. Today, 2010, 150, 2-7.

116 L. R. Radovic, I. F. Silva, J. I. Ume and J. A. Menbndez, Carbon N. Y., 1997, 35, 1339-1348.

117 H.-P. H. . Boehm, Carbon N. Y., 2002, 40, 145-149.

118 P. W. Albers, J. Pietsch, J. Krauter and S. F. Parker, Phys. Chem. Chem. Phys., 2003, 5, 1941-1949.

119 D. Lennon, D. T. Lundie, S. D. Jackson, G. J. Kelly and S. F. Parker, Langmuir, 2002, 18, 4667- 
4673.

120 P. Papanek, W. A. Kamitakahara, P. Zhou and J. E. Fischer, J. Phys. Condens. Matter, 2001, 8287, 8287.

121 R. Papoular, Fuel, 1995, 74, 865-873.

122 S. F. Parker, S. Imberti, S. K. Callear and P. W. Albers, Chem. Phys., 2013, 427, 44-48.

123 M. Casartelli, S. Casolo, G. F. Tantardini and R. Martinazzo, Carbon N. Y., 2014, 77, 165-174.

124 C. Cavallari, D. Pontiroli, M. Jiménez-Ruiz, A. Ivanov, M. Mazzani, M. Gaboardi, M. Aramini, M. Brunelli, M. Riccò and S. Rols, J. Phys. Conf. Ser., 2014, 554, 12009.

125 A. I. Kolesnikov, I. O. Bashkin, V. E. Antonov, D. Colognesi, J. Mayers and A. P. Moravsky, J. Alloys Compd., 2007, 446-447, 389-392.

126 Y. Liu, C. M. Brown, D. A. Neumann, D. B. Geohegan, A. A. Puretzky, C. M. Rouleau, H. Hu, D. Styers-Barnett, P. O. Krasnov and B. I. Yakobson, Carbon N. Y., 2012, 50, 4953-4964.

127 D. Pontiroli, M. Aramini, M. Gaboardi, M. Mazzani, S. Sanna, F. Caracciolo, P. Carretta, C. Cavallari, S. Rols, R. Tatti, L. Aversa, R. Verucchi and M. Riccò, J. Phys. Chem. C, 2014, 118, 71107116.

128 P. W. Albers, M. Lopez, G. Sextl, G. Jeske and S. E. Parker, J. Catal., 2004, 223, 44-53.

129 P. Albers, R. Burmeister, K. Seibold, G. Prescher, S. F. Parker and D. K. Ross, J. Catal., 1999, 181, $145-154$.

130 P. Albers, E. Auer, K. Ruth and S. F. Parker, J. Catal., 2000, 196, 174-179.

131 P. W. Albers, J. G. E. Krauter, D. K. Ross, R. G. Heidenreich, K. Köhler and S. F. Parker, Langmuir, 2004, 20, 8254-8260.

132 D. R. Jones, S. Iqbal, S. A. Kondrat, G. M. Lari, P. J. Miedziak, D. J. Morgan, S. F. Parker and G. J. Hutchings, Phys. Chem. Chem. Phys., 2016, 18, 17259-17264.

133 S. F. Parker, D. Adroja, M. Jiménez-Ruiz, M. Tischer, K. Möbus, S. D. Wieland and P. Albers, Phys. Chem. Chem. Phys., 2016, 18, 17196-17201.

134 M. Suleiman, J. Faupel, C. Borchers, H. U. Krebs, R. Kirchheim and A. Pundt, J. Alloys Compd., 2005, 404-406, 523-528.

135 C. S. Tsao, Y. Liu, H. Y. Chuang, H. H. Tseng, T. Y. Chen, C. H. Chen, M. S. Yu, Q. Li, A. Lueking and S. H. Chen, J. Phys. Chem. Lett., 2011, 2, 2322-2325.

136 P. W. Albers, W. Weber, K. Möbus, S. D. Wieland and S. F. Parker, Carbon N. Y., 2016, 109, 239245.

137 D. Lennon, J. McNamara, J. R. Phillips, R. M. Ibberson and S. F. Parker, Phys. Chem. Chem. Phys., 2000, 2, 4447-4451.

138 P. C. H. Mitchell, a J. Ramirez-Cuesta, S. F. Parker, J. Tomkinson and D. Thompsett, J. Phys. Chem. 
$B, 2003, \mathbf{1 0 7}, 6838-6845$.

139 A. Piovano, A. Lazzarini, R. Pellegrini, G. Leofanti, G. Agostini, S. Rudić, A. L. Bugaev, C. Lamberti and E. Groppo, Adv. Condens. Matter Phys., 2015, 2015, Article ID 803267, 8 pages.

140 F. Fillaux, R. Papoular, A. Lautiè and J. Tomkinson, Carbon N. Y., 1994, 32, 1325-1331.

141 J. P. Chen and S. Wu, 2004, 2233-2242.

142 J. Jaramillo, P. Modesto and V. Gómez-serrano, Fuel Process. Technol., 2010, 91, 1768-1775.

143 J. L. Figueiredo, M. F. R. Pereira, M. M. A. Freitas and J. J. M. Orfao, Carbon N. Y., 1999, 37, 13791389.

144 K. Refson and S. F. Parker, Chem. Open, 2015, 4, 620-625.

145 S. F. Parker, S. M. Bennington, J. W. Taylor, H. Herman, I. Silverwood, P. Albers and K. Refson, Phys. Chem. Chem. Phys., 2011, 13, 7789.

146 C. Cavallari, D. Pontiroli, M. Jimenez-Ruiz, M. Johnson, M. Aramini, M. Gaboardi, S. F. Parker, M. Ricco, 'b And, Ste and 'phane Rols*, Phys. Chem. Chem. Phys., 2016, 18, 24820-24824.

147 J. K. Walters, R. J. Newport, S. F. Parker and W. S. J.Phys.Condens. Matter, 1995, 7, 10059-10073. 